
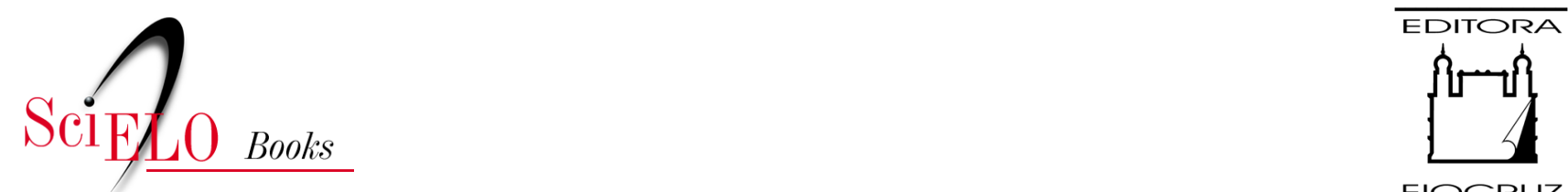

FIOCRUZ

\title{
4. Base mecânica, eletrônica e de materiais
}

\author{
José Maldonado Eduardo \\ Jorge Valadares Oliveira
}

\section{SciELO Books / SciELO Livros / SciELO Libros}

EDUARDO, J.M., and OLIVEIRA, J.V. Base mecânica, eletrônica e de materiais. In: GADELHA, C.A.G., GADELHA, P., NORONHA, J.C., and PEREIRA, T.R., eds. Brasil Saúde Amanhã: complexo econômico-industrial da saúde [online]. Rio de Janeiro: Editora FIOCRUZ, 2017, pp. 133172. ISBN: 978-65-5708-092-4. https://doi.org/10.7476/9786557080924.0006.

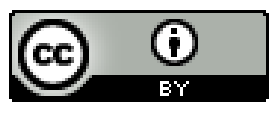

All the contents of this work, except where otherwise noted, is licensed under a Creative Commons Attribution $\underline{4.0 \text { International license. }}$

Todo o conteúdo deste trabalho, exceto quando houver ressalva, é publicado sob a licença Creative Commons Atribição 4.0.

Todo el contenido de esta obra, excepto donde se indique lo contrario, está bajo licencia de la licencia $\underline{\text { Creative }}$ Commons Reconocimento 4.0. 


\title{
BASE MECÂNICA, ELETRÔNICA E DE MATERIAIS
}

\author{
José Maldonado \\ Eduardo Jorge Valadares Oliveira
}

Dentre as atividades produtivas no âmbito do complexo econômico-industrial da saúde (CEIS) e em consonância com a base de conhecimento e tecnológica, destaca-se o subsistema de base mecânica, eletrônica e de materiais, que congrega um conjunto bastante díspar de atividades, usualmente agregadas na designada indústria de equipamentos e materiais médico-hospitalares e odontológicos. Essa indústria se constitui em uma área estratégica para a saúde, por representar uma fonte contínua de mudanças nas práticas assistenciais, exercendo particular influência na prestação de serviços de saúde. Tem, ademais, potencial de promover o adensamento do sistema nacional de inovação e de ampliar a competitividade industrial como um todo, dado que articula tecnologias portadoras de futuro.

A indústria de equipamentos e materiais médico-hospitalares e odontológicos tem um papel de destaque no âmbito do CEIS, tanto por seu potencial de inovação - incorpora fortemente os avanços associados ao paradigma microeletrônico - quanto por seu impacto nos serviços, e representa uma fonte constante de mudanças nas práticas assistenciais, trazendo permanentemente para o debate a tensão entre a lógica industrial e a sanitária. Esta indústria engloba grande variedade de produtos e tecnologias. Tomamos como referência a Global Medical Device Nomenclature (GMDN), cuja lista tem mais de oito mil nomes técnicos distintos. Estes se desdobram, de acordo com a Organização Mundial da Saúde (OMS), em cerca de 1,5 milhão de produtos diferentes, desde os mais tradicionais, como seringas e curativos, até os mais sofisticados, como os que incorporam bioinformática, nanotecnologia, eletrônica embarcada e engenharia de células e materiais.

A rigor, as indústrias de bioinformática, nanotecnologia, eletrônica embarcada e engenharia de células e materiais fogem ao escopo industrial tradicional. Entretanto, em virtude da grande variedade de produtos e serviços e da constante interação dessas indústrias com outros setores em geral e com a indústria de equipamentos e materiais médico-hospitalares e odontológicos em particular, criam um modelo de convergência tecnológica que, efetivamente, forma a base para uma importante fonte geradora de inovação.

A despeito de ser tratada como uma indústria, essa atividade abrange grande heterogeneidade tecnológica, pois incorpora, como já afirmado, segmentos bastante diversificados, desde bens de capital de alta complexidade até materiais de consumo de uso rotineiro. No Brasil, a Associação Brasileira da Indústria de Artigos e Equipamentos Médicos, Odontológicos, Hospitalares e de Laboratórios 
(Abimo), entidade que congrega as empresas dessa indústria, classifica as empresas conforme os seguintes segmentos: equipamentos médico-hospitalares; implantes; laboratório; odontologia; radiologia e materiais de consumo (Abimo, 2014).Essa característica abre amplas perspectivas em termos de diversos nichos competitivos que se configuram em oportunidades para empresas de diversas especialidades e porte.

No Brasil, apesar de tal indústria ter conhecido um crescimento significativo nos últimos anos, tem-se verificado um crescente déficit na balança comercial desses equipamentos e materiais. Tal incompatibilidade entre as necessidades nacionais de saúde e a base produtiva e inovativa da indústria aponta para fragilidades estruturais desta. Discutir as principais tendências que condicionam o desenvolvimento dessa indústria no Brasil e identificar nichos de mercado nos quais seja possível construir vantagens competitivas nacionais para 2030 são o objetivo central deste trabalho.

Dada a característica de grande heterogeneidade da indústria, na identificação de nichos de mercado optamos por dirigir um olhar mais minucioso para os segmentos de equipamentos médico-hospitalares, de implantes e de odontologia. Os dois primeiros por se tratar de produtos prioritários tanto para o Ministério da Saúde quanto para o Sistema Único de Saúde (SUS). E os equipamentos de odontologia, em função do seu desempenho competitivo: é o único segmento dessa indústria superavitário em termos de balança comercial.

\section{Panorama Global}

A indústria de equipamentos e materiais médico-hospitalares e odontológicos (produtos médicos) se constitui em um oligopólio baseado na diferenciação de produtos. Sua dinâmica de funcionamento assenta-se no fornecimento de bens, em grande parte altamente especializados, com grande quantidade de produtos sendo lançados continuamente, com novas opções de tratamento e diagnóstico, com ciclos tecnológicos curtos (com duração de menos de dois anos), e que são comercializados em associação com serviços e outros produtos (Leão, Oliveira \& Albornoz, 2008).

Nessa indústria, altamente concentrada, ${ }^{1}$ a diferenciação de produtos se baseia na intensidade dos gastos em pesquisa e desenvolvimento (P\&D), sendo que as grandes empresas concentram seus esforços competitivos em segmentos de maior intensidade tecnológica. Uma característica marcante dessa indústria é sua crescente absorção de avanços tecnológicos oriundos de indústrias tradicionalmente inovadoras, como as de microeletrônica, nanotecnologia, automação, mecânica de precisão, materiais etc.

Esse processo tem se tornado imprescindível para os avanços tecnológicos do setor, pois grande parte das incorporações tecnológicas nos produtos comercializados atualmente são desdobramentos (spill-overs) de outras indústrias. Dessa forma, os maiores atores (players) mundiais do setor não têm

\footnotetext{
${ }^{1}$ De acordo com ABDI (2009), as vinte maiores empresas respondem por aproximadamente $70 \%$ da produção mundial.
} 
o negócio "produto médico"2 como motor principal, capaz de impulsionar grandes investimentos em P\&D e arcar com os elevados custos da corrida tecnológica. Nessas empresas, o principal investimento em P\&D no setor (aproximadamente 13\% do faturamento para as empresas americanas e 7\% para as empresas europeias) consiste na adequação e adaptação do conteúdo tecnológico dos outros setores industriais para a área médica (Gadelha et al., 2012).

Isso explica o fato de as grandes empresas internacionais da indústria terem adotado estratégias comerciais em âmbito global, defendendo suas posições nos grandes mercados já estabelecidos Estados Unidos da América (EUA), Comunidade Europeia e Japão -, o que demanda produtos de alto conteúdo tecnológico. Além disso, estão buscando dominar mercados emergentes que crescem a taxas bastante elevadas e nos quais o mercado é caracterizado por produtos com conteúdo tecnológico inferior e custo-efetividade comprovados. Nesses mercados, à exceção dos EUA, a atenção à saúde é predominantemente patrocinada com recursos públicos e, com o aperfeiçoamento dos sistemas de saúde público e privado, a extensão da cobertura das redes de assistência a uma parcela cada vez maior da população e a expansão do gasto público em saúde têm demonstrado que os países emergentes passaram a ser o principal atrativo para as empresas do setor.

Apesar dessa forte característica de atividades intensivas em P\&D associadas a estratégias empresariais de penetração em diferentes mercados, grande quantidade de equipamentos e materiais de uso em saúde obedece a padrões de competição baseados em preços. É o caso de mercados de materiais médicos como seringas, luvas e equipamentos médicos para diagnósticos e terapias mais convencionais, em que a produção e os ganhos de competitividade se dão em largas escalas e as margens de lucro são reduzidas. No Brasil, esse é o principal mercado das empresas nacionais, conforme observado nos dados sobre comercialização do Sistema de Análise das Informações de Comércio Exterior via Internet (Aliceweb/MDIC) e sobre produção da Pesquisa Industrial Anual do Instituto Brasileiro de Geografia e Estatística (PIA/IBGE).

Além do dinamismo da corrida tecnológica, de vendas casadas, soluções integradas e linhas de financiamento atrativas, as grandes empresas que dominam o mercado internacional têm adotado duas outras estratégias fundamentais: a internacionalização e fusões/aquisições. No primeiro caso, as empresas estabelecem uma rede de prestação de serviços técnicos nos países em que atuam, com o intuito de aproximar as atividades de assistência e de manutenção dos usuários, além de distribuir plantas industriais em diversas localidades para minimizar custos de fabricação e aproveitar vantagens de infraestrutura e logística de transporte - especialmente com a produção asiática.

Por outro lado, a estratégia de fusão e aquisição de empresas ${ }^{3}$ em negócios internacionais visa à minimização de custos intangíveis muito importantes, como, por exemplo, a manutenção de pontos

\footnotetext{
${ }^{2}$ Produto médico, conforme a RDC Anvisa n. 185, de 22 de outubro de 2001, é "Produto para a saúde, tal como equipamento, aparelho, material, artigo ou sistema de uso ou aplicação médica, odontológica ou laboratorial, destinado à prevenção, diagnóstico, tratamento, reabilitação ou anticoncepção e que não utiliza meio farmacológico, imunológico ou metabólico para realizar sua principal função em seres humanos, podendo, entretanto, ser auxiliado em suas funções por tais meios".

${ }^{3}$ Na indústria, o processo de fusões e aquisições tem sido intenso. Em 2011, por exemplo, ocorreram 443 transações dessa natureza e, em 2012, 330 (Medical..., 2013).
} 
de promoção de vendas e redes de assistência técnica especializada. No Brasil, nos últimos dois anos, tem-se observado que essas empresas iniciaram um processo de aquisição das principais empresas nacionais nas áreas de imagem e monitoramento de sinais vitais. Os produtos fabricados localmente têm custo-efetividade e preço tais que lhes garantem uma significativa participação na rede pública de saúde. Em outras palavras, os equipamentos produzidos por essas empresas dominavam a base da pirâmide de um mercado público de saúde em expansão. Isso fez com que as grandes empresas internacionais vislumbrassem a possibilidade concreta de expandir seus negócios mediante a aquisição das principais empresas nacionais que contavam com uma rede de vendas e de assistência técnica capilarizada e grande inserção no mercado.

A curto prazo, essa abordagem se mostra interessante porque se espera observar um ganho de tecnologia nos produtos fabricados localmente e disponibilizados no sistema público de saúde, principalmente na melhoria dos aspectos de confiabilidade e usabilidade dos produtos. Contudo, a longo prazo não há garantia concreta da manutenção dessas empresas e da fabricação desses produtos no país, o que pode implicar, no caso de extinção das empresas, um desequilíbrio ainda maior da balança comercial e o aumento no preço para a aquisição de tecnologias médicas, uma vez que sem a presença das tecnologias custo-efetivas, ocorrerá a migração da demanda para as tecnologias consideradas como estado da arte.

O mercado mundial dessa indústria em 2013 era avaliado em US\$ 328 bilhões (The World..., 2013). O Gráfico 1 apresenta para esse ano a participação por região no mercado mundial. A Tabela 1, por sua vez, apresenta para 2013 a participação no mercado mundial, em valor e percentual, por principais países.

Das informações contidas no Gráfico 1 e na Tabela 1, constata-se a forte concentração da indústria nos países da tríade. Os dez maiores mercados respondem, em conjunto, por 77\% do total mundial, sendo que os EUA representam incontestavelmente o maior mercado, com 39\% do total. Dentre os designados Brics, os quatro países de economia mais robusta, Brasil, Rússia, Índia e China, representam em conjunto $10 \%$ do total mundial (a Índia, que no ranking ocupa a $16^{\mathrm{a}}$ posição, detém $1 \%$ do mercado mundial). 
Gráfico 1 - Distribuição percentual do mercado mundial por região - 2013

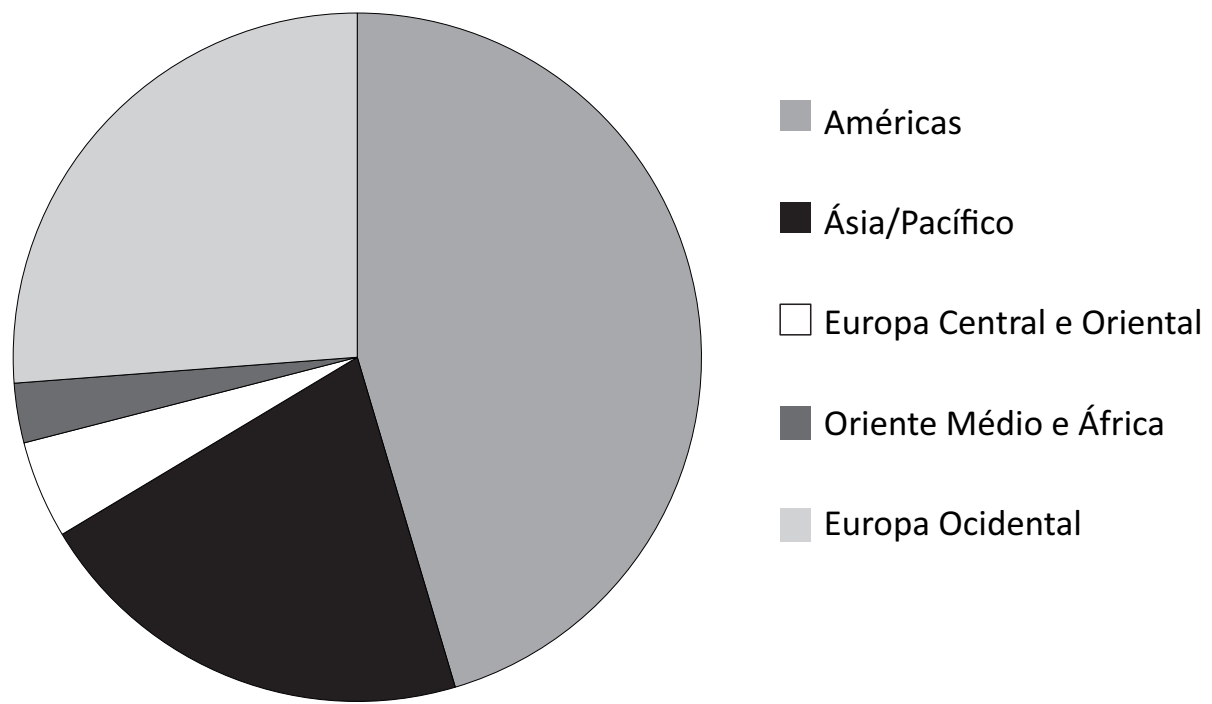

Fonte: The World Medical Markets Fact Book 2013.

A desaceleração das economias europeias nas duas últimas décadas, agravada pela crise mundial recente, tem estimulado a adoção de políticas de contenção de gastos por parte dos governos e das operadoras de saúde, contribuindo para uma estagnação relativa do mercado de equipamentos médicos nos países desenvolvidos. Em contrapartida, as perspectivas em termos de taxa de crescimento encontram-se nos países emergentes e, como afirmado, assiste-se a um crescente interesse das grandes multinacionais da indústria nesses mercados, cristalizado, em muitos casos, em um processo de aquisições e fusões de empresas locais detentoras de ativos estratégicos.

Tabela 1 - Participação no mercado mundial por principais países - 2013

\begin{tabular}{|ll|r|r|}
\hline & País & US\$ milhões & $\%$ \\
\hline 1 & EUA & 127.098 & 39,0 \\
\hline 2 & Japão & 29.750 & 9,0 \\
\hline 3 & Alemanha & 25.662 & 8,0 \\
\hline 4 & China & 17.146 & 5,0 \\
\hline 5 & França & 14.863 & 4,0 \\
6 & Grã-Bretanha & 9.896 & 3,0 \\
7 & Itália & 9.096 & 3,0 \\
\hline 8 & Rússia & 7.434 & 2,0 \\
\hline 9 & Canadá & 7.277 & 2,0 \\
10 & Brasil & 5.919 & 2,0 \\
& Outros & 73.571 & 23,0 \\
\hline
\end{tabular}

Fonte: The World Medical Markets Fact Book 2013. 
Os EUA são, sem dúvida, o grande player da indústria em termos de dimensão do mercado doméstico, tamanho das suas empresas e participação no comércio mundial. De acordo com Leão, Oliveira e Albornoz (2008), o sucesso das empresas norte-americanas nessa indústria é resultado da convergência de um conjunto de fatores: o ambiente institucional e empresarial no qual as empresas estão inseridas; a extensão do mercado privado dos serviços de saúde com ampla capacidade de absorção de uma oferta crescente de novos produtos; a forte atuação do governo na abertura e acesso a novos mercados e o engajamento tradicional das empresas em P\&D. Além de cadeias produtivas em todos os segmentos, a existência de indústrias correlatas como as de microeletrônica, telecomunicações, instrumentação, biotecnologia, desenvolvimento de software, entre outras, completa essa perspectiva (Selan, Porto \& Kannebley, 2007).

Por não terem a mesma capacidade tecnológica e industrial, os demais países concorrentes, especialmente os europeus e o Japão, desenvolvem estratégias de especialização e de segmentação. A Alemanha, por exemplo, procurou se especializar no segmento de diagnóstico por imagem, no qual a principal empresa é a Siemens, e no de implantes. O Japão, por sua vez, se destaca principalmente em aparelhos de ultrassonografia, aparelhos de eletrodiagnóstico e de instrumentos oftálmicos (Selan, Porto \& Kannebley, 2007).

\section{Dinâmica de inovação}

A competência tecnológica de um setor é um conjunto que engloba desde a habilidade individual até a capacidade de integração e sinergia das empresas, envolvendo perícia, especialidade técnica, gerencial e institucional. Essa articulação é altamente dependente, entre outras coisas, de educação e qualificação de pessoal. É graças à capacitação e qualificação de seu pessoal técnico que uma nação ou região pode assimilar os novos conhecimentos e aplicá-los nos processos produtivos e nas atividades de pesquisa, desenvolvimento e inovação (PD\&I), criando assim um ambiente favorável à inovação tecnológica (Oliveira, 2001). Ainda de acordo com esse autor, "o fator tecnológico é imprescindível para a vitalidade da economia. A inovação tecnológica é responsável pelo rompimento ou aperfeiçoamento das técnicas e processos de produção. Pode, desta forma, trazer ganhos em termos de competitividade" (Oliveira, 2001: 6).

Segundo Cassiolato e Lastres (2000), os principais fatores que contribuíram para o melhor entendimento do processo de inovação nos últimos anos foram:

1) o reconhecimento de que inovação e conhecimento (ao invés de serem considerados como fenômenos marginais) colocam-se, cada vez mais visivelmente, como elementos centrais da dinâmica e do crescimento de nações, regiões, setores, organizações e instituições;

2) a compreensão de que a inovação constitui-se em processo de busca e aprendizado, o qual, dependente de interações, é socialmente determinado e fortemente influenciado por formatos institucionais e organizacionais específicos;

3) a ideia de que há marcantes diferenças entre os agentes e suas capacidades de aprender (as quais refletem e dependem de aprendizados anteriores, assim como da própria capacidade de esquecer); 
4) o entendimento de que há importantes diferenças entre sistemas de inovação de países, regiões, setores, organizações etc. em função de cada contexto social, político e institucional específico;

5) a visão de que, se por um lado informações e conhecimentos codificados apresentam condições crescentes de transferência - dada a eficiente difusão das tecnologias da informação e comunicação (TICs) -, conhecimentos tácitos de caráter localizado e específico continuam tendo papel primordial para o sucesso inovativo e permanecem de difícil (senão impossível) transferência.

Assim, as principais tendências relativas às novas especificidades do processo inovativo, observadas na última década do século XX, podem ser destacadas. Inicialmente observou-se significativa aceleração da mudança tecnológica nas últimas décadas. O acontecimento é constantemente ilustrado pelos fatos de que: o tempo necessário para o lançamento de novos produtos tem se reduzido; o processo que leva à produção do conhecimento até a comercialização é mais curto; e os ciclos de vida dos produtos são também menores. Ademais, o uso amplo das TICs desempenha, certamente, papel fundamental nessa mudança (Cassiolato \& Lastres, 2000).

Simultaneamente, a cooperação entre as empresas e a estruturação de redes industriais intersetoriais têm marcado o processo inovativo. O desenvolvimento de novos produtos é cada vez mais corriqueiro a partir da integração de diferentes tecnologias, estas crescentemente baseadas em conhecimentos multidisciplinares. Até mesmo as grandes corporações têm dificuldade em dominar os vastos domínios científicos e tecnológicos já conhecidos, o que torna necessária a expansão de acordos de cooperação e a crescente expansão de redes industriais intersetoriais.

Na visão de Cassiolato e Lastres (2000), a integração funcional e a montagem de redes têm oferecido vantagens às empresas na busca da rapidez no processo inovativo. A flexibilidade, a interdisciplinaridade e a fertilização cruzada de ideias, nos níveis administrativo e laboratorial, são importantes elementos do sucesso competitivo das empresas.

Nesse contexto, constata-se que o desenvolvimento econômico não está condicionado à idade de uma sociedade ou de um país. Para Furtado (1964), o subdesenvolvimento e o desenvolvimento estão relacionados ao grau de acumulação de capital aplicado aos processos produtivos e à heterogeneidade tecnológica de uma economia. Foi o processo de acumulação de capitais, avanços e difusão tecnológica que possibilitou e promoveu a diferenciação entre as sociedades industriais e as agrárias (Cassiolato \& Lastres, 2000).

Neste ponto, é necessário esclarecer a diferença entre modernização e difusão da inovação. O primeiro caso se refere à transferência, a partir do ente mais desenvolvido industrialmente para o menos desenvolvido, da imagem projetada do próprio futuro deste último. O segundo está relacionado ao reconhecimento do conhecimento como principal elemento do processo de inovação e de que seu uso geralmente proporciona o seu incremento.

Na visão de Furtado (1964), a modernização é o processo de adoção de modelos sofisticados de consumo sem que haja uma correspondente acumulação de capitais ou de progresso nos meios de produção, ou seja, a modernização está relacionada ao subdesenvolvimento, isto é, ao desenvolvimento 
dependente. Desenvolvimento, por sua vez, pode ser definido como "um processo de mudança social pelo qual o crescente número de necessidades humanas (...) são satisfeitas através de uma diferenciação no sistema produtivo, gerado pela introdução de inovações tecnológicas" (Furtado, 1964: 27).

A relação entre saúde e desenvolvimento começa a ser analisada por alguns autores (Viana, Gadelha, Machado, Lima, Baptista, Maldonado, Oliveira, Costa, Vargas, Cassiolato, por exemplo) que, utilizando-se do arcabouço teórico da economia política, propõem uma análise sistêmica dos seus condicionantes, superando assim uma abordagem estritamente setorial (social). Em relação à saúde, destaca-se tanto sua importância sociossanitária como elemento estruturante do Estado de bem-estar e condição básica de cidadania para a população quanto seus aspectos econômicos relacionados à sua base produtiva e inovativa (CEIS) naquilo que diz respeito à geração de investimento, emprego, renda e, sobretudo, na inovação, isto é, variáveis cruciais para o desenvolvimento.

Como elemento constituinte do CEIS, a indústria de equipamentos e materiais médico-hospitalares e odontológicos, por ser intensiva em CT\&I, é responsável pela permanente introdução de inovações no que tange a novos equipamentos e materiais que propiciem aumento da qualidade dos padrões de tratamento e diagnóstico para que estes sejam mais efetivos, mais rápidos, mais seguros e menos invasivos. Assim, se constitui em uma área-chave por seu potencial intrínseco de promover o adensamento do sistema nacional de inovação e de ampliar a competitividade da indústria como um todo. Trata-se de uma indústria portadora do futuro, por ser fonte geradora de inovações, por demandar e incorporar fortemente avanços tecnológicos oriundos de outras indústrias tradicionalmente inovadoras, e por suas inter-relações dinâmicas tanto no interior do CEIS, em particular, como no âmbito da atividade econômica como um todo.

Ao se constituir num oligopólio diferenciado, a competição na indústria, como afirmado, se dá via diferenciação de produtos, baseada na intensidade dos gastos em P\&D. A Tabela 2 apresenta, para 2006 e 2011, as dez empresas do mundo que mais investem em P\&D na indústria, especificando para cada uma o montante investido e o percentual sobre vendas.

Constata-se o significativo percentual dos recursos aplicados na rubrica P\&D sobre vendas, o que atesta claramente a importância da intensidade de gastos em P\&D na dinâmica competitiva da indústria. Verifica-se, igualmente, a forte presença de empresas norte-americanas dentre aquelas que mais investem em P\&D.

A indústria de equipamentos e materiais médico-hospitalares e odontológicos tem apresentado um dinamismo significativo, nos últimos anos decorrente da incorporação de avanços tecnológicos, que tem significado o constante desenvolvimento de novos produtos com novas funções, a ampliação da demanda por serviços de saúde em função do envelhecimento da população, sobretudo nos países desenvolvidos, e o crescimento do mercado principalmente dos países emergentes, no que tange à reformulação e ampliação dos sistemas de saúde (Gutierrez \& Alexandre, 2004). 
Tabela 2 - Empresas que mais investem em pesquisa e desenvolvimento na indústria - 2006 e 2011(em $£$ milh.)

\begin{tabular}{|c|c|c|c|c|c|c|c|}
\hline \multicolumn{4}{|c|}{2006} & \multicolumn{4}{|c|}{2011} \\
\hline Empresa & País & $\begin{array}{l}\text { Inv. P\&D } \\
\text { ( } £ \text { milh.) }\end{array}$ & $\begin{array}{l}\% \text { das } \\
\text { vendas }\end{array}$ & Empresa & País & $\begin{array}{l}\text { Inv. P\&D } \\
\text { ( } £ \text { milh.) }\end{array}$ & $\begin{array}{l}\% \text { das } \\
\text { vendas }\end{array}$ \\
\hline Medtronic & USA & 633,05 & 10,1 & Medtronic & USA & $1.165,5$ & 9,3 \\
\hline $\begin{array}{l}\text { Boston } \\
\text { Scientific }\end{array}$ & USA & 515,02 & n. d. & $\begin{array}{l}\text { Baxter } \\
\text { International }\end{array}$ & USA & 731,1 & 6,8 \\
\hline $\begin{array}{l}\text { Baxter } \\
\text { International }\end{array}$ & USA & 313,71 & 5,9 & $\begin{array}{l}\text { Boston } \\
\text { Scientific }\end{array}$ & USA & 691,7 & 11,7 \\
\hline $\begin{array}{l}\text { Saint Jude } \\
\text { Medical }\end{array}$ & USA & 220,27 & 13,1 & Olympus & JPN & 610,1 & 7,2 \\
\hline $\begin{array}{l}\text { Becton } \\
\text { Dickinson }\end{array}$ & USA & 183,94 & 6,2 & $\begin{array}{l}\text { Saint Jude } \\
\text { Medical }\end{array}$ & USA & 544,9 & 12,6 \\
\hline Carl Zeiss & $\mathrm{CHN}$ & 167,59 & 10,2 & Covidien & IRL & 428,2 & 5,0 \\
\hline Stryker & USA & 165,85 & 6,0 & $\begin{array}{l}\text { Becton } \\
\text { Dickinson }\end{array}$ & USA & 368,3 & 6,3 \\
\hline $\begin{array}{l}\text { Beckman } \\
\text { Coulter }\end{array}$ & USA & 135,35 & 10,5 & Stryker & USA & 357,1 & 5,6 \\
\hline Fresenius & DEU & 112,52 & 1,6 & Carl Zeiss & DEU & 354,5 & 8,4 \\
\hline Zimmer & USA & 96,21 & 5,4 & Fresenius & DEU & 267,0 & 1,6 \\
\hline
\end{tabular}

n. d. - dado não disponível.

Fontes: European Commission, 2007, 2013.

A ampliação da demanda e da oferta dos serviços de saúde e o próprio desenvolvimento tecnológico da indústria estão estreitamente ligados. De um lado, as empresas, ao disponibilizarem novos equipamentos, direcionam a demanda dos serviços da saúde no sentido da incorporação destes novos equipamentos e tratamentos alternativos. De outro, essa incorporação retroalimenta o processo de inovação das empresas ao impor melhorias sucessivas nos equipamentos. Ou seja, a esfera do consumo desempenha também um papel crucial no processo inovativo das empresas.

Vale salientar que nessa indústria o processo de inovação não ocorre somente nos laboratórios industriais, mas também na prática clínica, uma vez que é nela que se identificam a necessidade e a possibilidade de um novo equipamento, a criação do primeiro protótipo e aprimoramentos decisivos para o desenvolvimento do equipamento (Albuquerque \& Cassiolato, 2000).

Em um ambiente crescentemente competitivo, além da atividade formal de P\&D, as empresas desenvolvem outras estratégias de apropriação externa de conhecimento, seja na forma de acordos de colaboração, seja em processos interativos com outros agentes socioeconômicos, isto é, fusões e aquisições, alianças (joint ventures, acordos de $\mathrm{P} \& \mathrm{D}$, acordos de marketing) e acordos de financiamento (Gadelha et al., 2012).

Um dos focos centrais do debate da inovação tecnológica em nível mundial e o seu impacto sobre o gasto em saúde diz respeito à sustentabilidade da incorporação de novas tecnologias, 
tratamentos e métodos de diagnóstico no gasto social (privado e público) com saúde. Evidências empíricas e estudos de caso em diversos países têm indicado o surgimento, progressivamente mais acentuado, de novas tecnologias para a saúde como o principal responsável pela expansão da proporção do gasto com saúde na renda nacional. A dinâmica de constantes incrementos tecnológicos da indústria de equipamentos e materiais médico-hospitalares e odontológicos, aliada à expansão da cobertura da assistência à saúde, nos países desenvolvidos (e mais recentemente nos países em desenvolvimento) são, atualmente, os dois fatores que mais influenciam o aumento explosivo do custo da assistência à saúde.

Em meio a um padrão global de inovações tecnológicas, que se move da pesquisa básica de novos tratamentos para soluções tecnologicamente mais sofisticadas, a introdução de novos produtos e soluções tecnológicas tem se tornado cada vez mais frequente, reduzindo os ciclos tecnológicos dos produtos (Rasmussen, Annerstedt \& Graham, 2007).

Por outro lado, em decorrência do envelhecimento da população, o aumento da renda per capita - que possibilita o aumento da demanda por serviços de saúde - e a própria problemática da incorporação de tecnologias nos sistemas de saúde têm sido os maiores responsáveis pelo aumento dos gastos em saúde. Do ponto de vista das contas nacionais, o problema da expansão do gasto com saúde é que o seu crescimento tem sido maior que o crescimento da renda nacional de diversos países, especialmente dos países europeus, onde a expectativa de vida e a renda per capita são extremamente elevadas e o serviço de saúde é majoritariamente público.

Nas últimas duas décadas, com a desaceleração do ritmo de crescimento das economias europeias, a pressão sobre o orçamento público advinda dos cuidados com a saúde da população tem representado um dos maiores desafios em termos de política pública no mundo ocidental (Pammolli et al., 2005). Portanto, fica evidente a existência de um trade-off (acordo) entre o incentivo à inovação tecnológica no seio dessa indústria e a necessidade atual dos governos em todo o mundo, especialmente no Brasil, de conter a expansão desordenada dos gastos públicos com assistência à saúde.

O que se divulga na literatura sobre o tema é que há uma relação de causa e consequência entre o comportamento inovador das empresas da indústria e a expansão dos serviços de atenção à saúde, de maneira que o crescimento dos gastos nacionais com cuidados da saúde tende, a longo prazo, a crescer ininterruptamente em ritmos cada vez mais acentuados. De maneira geral, a avaliação dos benefícios oriundos da ampliação dos padrões tecnológicos carece de bases teóricas mais sólidas, o que torna difícil avaliar, do ponto de vista do bem-estar social, se a expansão do gasto com novas tecnologias é acompanhada por um incremento, pelo menos na mesma proporção, dos benefícios aos pacientes e aos sistemas de saúde. Assim, não se sabe, a priori, se o aumento do gasto é justificado ou não (do ponto de vista econômico, isto é, considerando-se o custo-efetividade das novas tecnologias). Nessa perspectiva, há duas formas de relacionar o gasto com pesquisa e desenvolvimento de novas tecnologias e a expansão dos sistemas de serviços de saúde: na primeira se afirma que o gasto com P\&D em saúde é uma resposta à expansão dos serviços de saúde, e na segunda se diz que a maior cobertura dos serviços é uma consequência do aumento do gasto com P\&D (Pammolli et al., 2005).

No primeiro caso, a intensidade do gasto com P\&D depende de uma série de fatores, dentre os quais o retorno esperado do investimento, o tamanho do mercado para o novo produto ou serviço 
disponível e o seu preço esperado, que é determinado pelos sistemas públicos e privados de assistência à saúde. Neste último fator, a ação dos planos de saúde privados e os programas públicos têm influência significativa sobre a aceitação da nova tecnologia e seus reais usos no sistema de saúde, determinando assim, em última instância, a intensidade do investimento em P\&D. Uma vez que ampliam seus recursos de investimentos, os sistemas de saúde (públicos e privados) permitem que os pacientes tenham acesso a novas soluções tecnológicas, incentivando ainda mais o incremento dos investimentos em inovação tecnológica.

No segundo caso, a demanda por planos de saúde (públicos ou privados) depende, em parte, de mudanças e avanços tecnológicos: se uma nova solução tecnológica coloca à disposição da sociedade um novo tratamento - mais eficaz ou inédito - que possibilita a cura ou aumenta a expectativa de vida de pacientes, mesmo que com custo muito mais elevado que a opção trivial, então a sociedade pode, a longo prazo, expandir suas possibilidades de gasto com serviços de saúde e, assim, exigir ou demandar ainda mais coberturas assistenciais que possam oferecer os novos tratamentos. Portanto, o eventual benefício da "nova solução tecnológica" pode resultar em pressão política e social sobre as autoridades públicas, para que estas tornem as inovações acessíveis e disponíveis para a coletividade, independentemente da capacidade de pagamento existente. Isso é observado no processo de judicialização do SUS, situação que não apenas leva ao aumento da demanda nos planos privados, mas também aumenta as pressões para que a cobertura do sistema público seja cada vez maior.

Novas tecnologias e novos tratamentos aumentam a magnitude do gasto com serviços de saúde, e assim direcionam a demanda por programas públicos e privados de assistência à saúde - programas estes que incluam não somente mais pessoas, mas cada vez mais tecnologias e tratamentos alternativos e inovadores. Por outro lado, a expansão da cobertura e a incorporação de novos tratamentos e soluções, por parte dos programas de saúde, incentivam a inovação tecnológica e o aparecimento, cada vez maior, de produtos e serviços de saúde, pois facilita à população o acesso a novos tratamentos e tecnologias. Para se ter uma ideia disso, dados da OMS registram que no ano 2000 oito mil novos produtos foram inseridos no mercado americano (WHO, 2012) e, de acordo com dados da Agência Nacional de Vigilância Sanitária (Anvisa), em 2012 cerca de 14.300 novos produtos foram disponibilizados no Brasil (Anvisa, 2012).

Outra questão relacionada à influência dos planos de saúde sobre a inovação tecnológica concerne ao modelo de pagamento dos serviços de saúde. Até meados dos anos 1980, os planos de saúde pagavam os tratamentos com base nos custos incorridos e derivados de cada caso específico. Esse modelo de pagamento incentivava o uso irracional e abusivo de diagnósticos, tratamentos e soluções apresentados ao paciente, o que ocasionava uma pressão muito grande sobre o orçamento do plano de saúde, pois o médico/hospital tinha flexibilidade para induzir o consumo do paciente, tendo a garantia de que o plano de saúde cobriria todos os custos. Depois de perceberem essa prática de mercado, os planos de saúde dos EUA inovaram no modelo de pagamento de serviços de saúde, estabelecendo preços e pagamentos em pacotes fechados, que independiam do total dos custos incorridos pelo médico/hospital no tratamento ou uso de qualquer solução tecnológica disponível.

Nesse caso, no qual a receita do hospital é dada de forma exógena e fixa, a lucratividade dos hospitais passou a depender da sua eficiência administrativa em gerir os custos e as consequências 
de suas decisões no tratamento de enfermidades (Pammolli et al., 2005). No primeiro modelo, a sinalização de mercado no que concerne à inovação tecnológica levava as indústrias de equipamentos e materiais de uso em saúde a lançarem novos produtos e serviços tecnologicamente mais sofisticados, independentemente de seus potenciais custos. No segundo modelo, a sinalização de mercado é mais parcimoniosa: as indústrias passaram a ter o incentivo para desenvolver novas tecnologias capazes de reduzir os custos dos tratamentos, sem prejuízo da qualidade.

Antes da pressão sobre os orçamentos públicos e privados de saúde e da demasiada expansão da demanda por serviços de saúde, novas tecnologias e serviços mais avançados que possibilitassem pequenas melhorias de tratamento e diagnósticos eram incondicionalmente incorporados aos sistemas de saúde, de maneira que a sinalização de mercado para a indústria era sempre focada no incremento e na melhoria do produto ou serviço de saúde, e não em eficiência e redução de custos. No entanto, com o aumento continuamente crescente da pressão do gasto com saúde nos orçamentos públicos e privados, a mudança do modelo de pagamento ocorrida nos anos 1980 não deixou de influenciar a indústria no investimento em melhorias tecnológicas e aumento dos padrões de tratamento e diagnóstico, mas a levou a considerar a eficiência e o custo de suas soluções tecnológicas no desenvolvimento de novas tecnologias de saúde.

Mesmo a partir dessa mudança no sistema de pagamentos dos serviços de saúde, com o incentivo e a consequente introdução de tecnologias cada vez mais eficientes, que proporcionaram reduções do custo médio dos tratamentos disponíveis, o gasto com saúde continuou crescente, sem perspectivas de redução do seu custo total. A explicação para esse fenômeno está em cinco causas distintas (Pammolli et al., 2005):

1) várias tecnologias médicas que se mostraram eficientes e proporcionaram reduções de custo unitário passaram a ser utilizadas em uma variedade cada vez maior de tipos de doença e opções de tratamento alternativas, o que acabou levando ao aumento do custo total com essas tecnologias;

2) as novas soluções tecnológicas possibilitaram à medicina condições de adentrar em tratamentos e diagnósticos antes inexplorados, o que ampliou o gasto com saúde, por abrir novos mercados para novos tratamentos;

3) quando novas tecnologias permitem avanços nos tratamentos e redução de custos dos tratamentos já disponíveis, é de se esperar que essas soluções tecnológicas sejam estendidas a um número maior de pacientes - quando uma tecnologia reduz o custo unitário e aumenta a qualidade do tratamento, o custo total com essa tecnologia tende a aumentar;

4) a melhoria das condições de tratamento de doenças e os avanços tecnológicos da medicina moderna têm ampliado o conceito de doença e enfermidade, o que leva os sistemas de saúde a incorporar esses novos conceitos, provocando aumento de custos;

5) o avanço das técnicas de tratamento proporcionado pelos avanços tecnológicos aumenta a expectativa de vida, e mesmo que o custo unitário e anual dos tratamentos seja reduzido, o custo total aumenta devido à sobrevida dos pacientes. 


\section{Panorama Nacional}

A indústria brasileira de produtos médicos surgiu na década de 50 do século XX e alcançou o seu ápice nos anos 70. Nas últimas três décadas, transformações no cenário nacional e internacional trouxeram novos desafios à indústria. A abertura de mercado na década de 1990 esgotou o modelo formal de substituição de importações e promoveu o surgimento de um novo ambiente concorrencial. A regulação do mercado iniciada pelo Ministério da Saúde em 1992 e seus desdobramentos catalisados pela Anvisa trouxeram à tona novos conceitos e a exigência de padrões mínimos de qualidade para a indústria.

É importante destacar que se, por um lado, novos fatores regulatório-econômicos tornaram mais árdua a expansão da indústria, por outro induziram uma significativa melhora na qualidade das tecnologias fabricadas no país. Isso pode ser observado quando se analisam os dados da Pesquisa Industrial de Inovação Tecnológica (Pintec), do IBGE, na qual a indústria de produtos médicos aparece como uma das mais inovadoras. Desde então, novos conceitos regulatórios foram fortemente introduzidos no mercado: boas práticas de fabricação (BPF) e certificação compulsória de equipamentos, no âmbito do Instituto Nacional de Metrologia, Normalização e Qualidade Industrial (Inmetro).

Esses aspectos, associados ao crescimento da demanda interna, à ampliação do SUS e ao peso da demanda pública nesse mercado, foram responsáveis pela significativa expansão da indústria a partir da segunda metade da década de 1990. Nesse contexto, assistiu-se a um significativo crescimento da indústria nos anos recentes, capaz de responder por cerca de $50 \%$ da demanda nacional, gerando cerca de cem mil empregos no país e atingindo um valor da produção industrial de $\mathrm{R} \$ 4,8$ bilhões em 2012 (Abimo, 2013a).

O Gráfico 2 apresenta a evolução do valor da produção no período 2005-2012, desagregado por principais segmentos. Verifica-se que o valor da produção da indústria tem crescido de modo expressivo, sobretudo a partir de 2009. Descontada a variação de preços, a produção setorial cresceu em média 3,9\% a. a. no período de 2007 a 2012 (Abimo, 2013b).

Considerando os quatro segmentos analisados, o desempenho real da produção para esse mesmo período foi de 5,5\% para equipamentos médicos, $16,2 \%$ para implantes, 7,2\% para materiais odontológicos e uma variação negativa, de $-6,3 \%$, para materiais de consumo. Vale mencionar que a produção da indústria de transformação brasileira cresceu apenas 0,6\% ao ano em média, o que mostra a evolução bastante favorável da indústria (Abimo, 2013b). 
Gráfico 2 - Evolução do valor da produção, por segmento. Brasil - 2005-2012 (em R\$ bilhões)

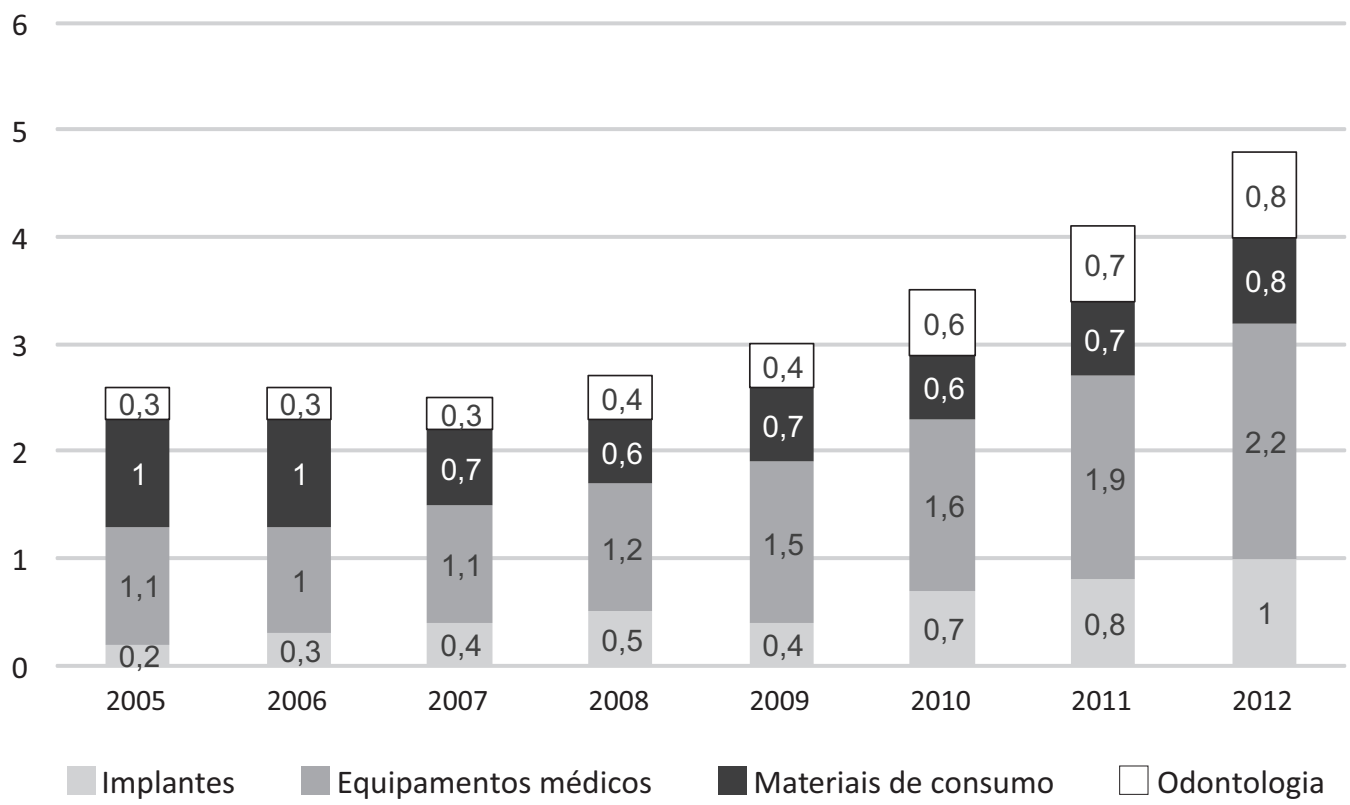

Fonte: Abimo, 2013b.

Apesar desse comportamento positivo, tem-se assistido a um crescimento do déficit comercial nos anos recentes, o que sinaliza a perda de competitividade da indústria, notadamente nos produtos de maior intensidade tecnológica. Além disso, a produção realizada por empresas situadas no território nacional ainda depende fortemente de insumos importados de maior conteúdo tecnológico, com tal dependência chegando a atingir 50\% em alguns segmentos. O Gráfico 3 apresenta a evolução da balança comercial da indústria de 1996 a 2013.

O déficit comercial, que em meados da década de 1990 e início dos anos 2000 girava em torno de US $\$ 800$ milhões ao ano, a partir de 2007 conhece um crescimento acentuado, chegando em 2013 ao patamar de US\$ 3 bilhões. Deve-se salientar que o déficit da indústria de equipamentos e materiais médico-hospitalares e odontológicos representa $24 \%$ do total do CEIS, logo atrás do déficit da indústria farmacêutica, de $25 \%$ do total (GIS, 2014). 
Gráfico 3 - Evolução da balança comercial de equipamentos e materiais. Brasil - 1996-2013 (valores em US\$ bilhões, atualizados pelo IPC/EUA)

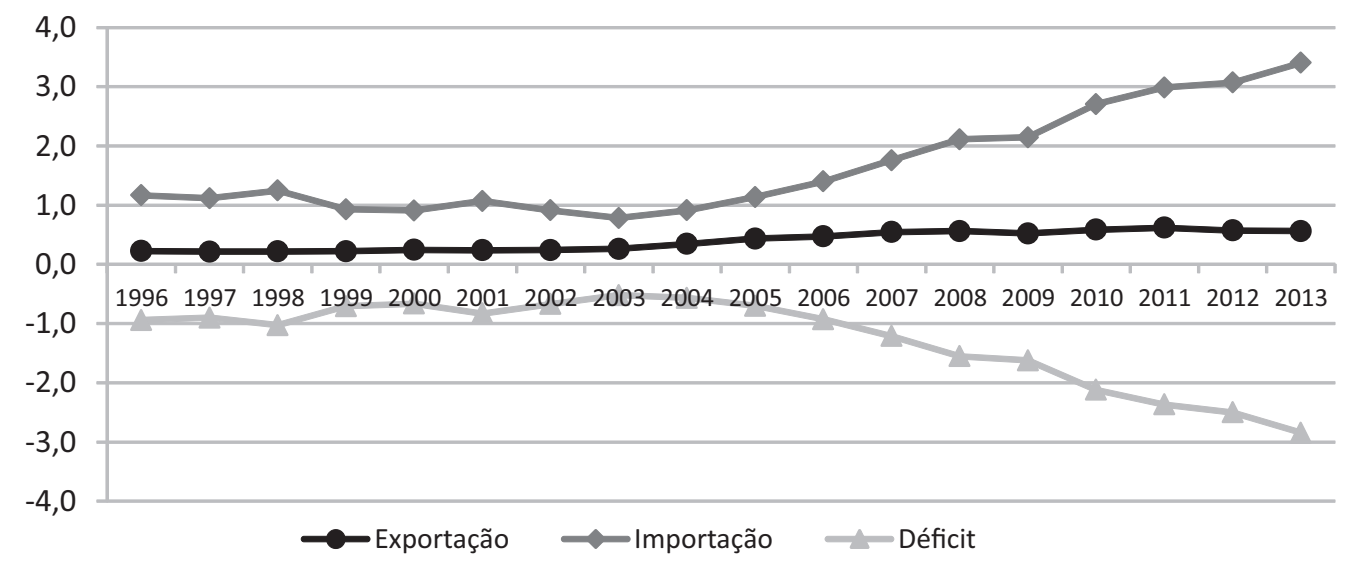

Fonte: elaborado pelo Grupo de Pesquisa de Inovação em Saúde da Escola Nacional de Saúde Pública Sergio Arouca (GIS/Ensp/Fiocruz), com base em dados da Rede Alice/MDIC.

Esse déficit comercial sinaliza a defasagem tecnológica da indústria, que, associada a diversos fatores institucionais, limita o potencial inovador das empresas nacionais. O Brasil não tem condições de reverter o quadro de dependência de importações de produtos tecnologicamente complexos, e muito menos de organizar estratégias reais de inserção nos mercados de alta tecnologia, pelo menos a curto prazo. Por outro lado, o país, paulatinamente, vem, ao longo das últimas décadas, perdendo competitividade no nicho de mercado em que se especializou - produtos de baixa intensidade tecnológica, produzidos em larga escala e com baixas margens de lucro - para países como China e Cingapura. Nesses países, diversas questões institucionais (baixos padrões de regulação sanitária e ausência de legislação trabalhista, por exemplo) reduzem de maneira expressiva os custos de produção e permitem colocar produtos no mercado internacional a preços extremamente competitivos.

\section{Dinâmica de inovação}

De modo geral, os produtos médicos podem ser agrupados em dois segmentos: os de alta tecnologia e os mais convencionais. O segmento de alta tecnologia é composto por dispositivos sofisticados destinados a usos terapêuticos e diagnósticos. Estão associados a atividades de P\&D de alto risco, pesquisas clínicas e processos administrativos e regulatórios para acesso ao mercado. Os produtos desse segmento têm um grande potencial de crescimento, principalmente, nos mercados privado e suplementar de saúde. Contudo, nele o risco da rápida obsolescência da tecnologia é elevado.

O segmento de produtos convencionais consiste em produtos como seringas, gaze, produtos intravenosos, bem como em uma grande gama de produtos para fins de diagnóstico e terapia. Está associado a baixas margens de lucro e grandes volumes de produção.

Observa-se que a dinâmica tecnológica do setor permite inferir como tendências a miniaturização, dispositivos inteligentes minimamente invasivos, produtos combinados, órgãos artificiais, tecnologia da informação, uso doméstico e produtos destinados a populações especiais. Os produtos com maior 
intensidade tecnológica são, geralmente, destinados aos mercados de saúde privada e suplementar, uma vez que, notadamente, oneram os custos da atenção à saúde.

Um fato a ser observado é que a constante evolução tecnológica dos materiais e componentes utilizados na fabricação dos produtos médicos faz com que haja no mercado produtos com ciclo de vida cada vez mais curto (de 18 a 24 meses). Isso traz duas consequências: a primeira é que, para os produtos de alta tecnologia, é muito provável que ocorra obsolescência antes de se conhecerem todos os seus potenciais benefícios, ou malefícios. A segunda é que muitas empresas estão deixando de patentear seus produtos, o que leva a resultados negativos na avaliação de seus bens intangíveis.

No Brasil, essa dinâmica da evolução tecnológica do setor, aliada à defasagem tecnológica, configura uma crescente dependência em importações sobretudo em produtos de alta tecnologia. Isso inclui desde produtos de alto valor unitário, como equipamentos de ultrassom e de ressonância magnética, tomógrafos etc., até, como afirmado, produtos de menor densidade tecnológica como stents, luvas, marca-passos e outros produtos de preço relativo baixo, vendidos em grande volume. Os principais importadores são hospitais públicos, instituições não lucrativas e empresas importadoras.

Essa crescente dependência atesta, na realidade, a baixa capacidade inovativa do parque fabril brasileiro. Tendo como base as informações da pesquisa Pintec/IBGE 2003, 2005 e 2011, a Tabela 3 apresenta alguns indicadores relacionados ao esforço inovativo da indústria de equipamentos e materiais médico-hospitalares e odontológicos comparativamente à indústria nacional, naqueles anos.

Tabela 3 - Atividades inovativas. Brasil - 2003, 2005 e 2011

\begin{tabular}{|l|c|c|c|c|c|c|}
\hline & \multicolumn{7}{c|}{ Incidência sobre receita líquida de vendas dos gastos em } \\
\hline & \multicolumn{5}{c|}{ Atividades inovativas } & \multicolumn{3}{c|}{ P\&D internos } \\
\hline $\begin{array}{l}\text { Total da indústria } \\
\text { brasileira }\end{array}$ & 2003 & 2005 & 2011 & 2003 & 2005 & 2011 \\
\hline $\begin{array}{l}\text { Indústria de } \\
\text { equipamentos } \\
\text { médicos }\end{array}$ & 3,1 & 2,8 & 4,6 & 0,5 & 0,6 & 2,2 \\
\hline
\end{tabular}

Fonte: Pintec (IBGE, 2003, 2005, 2011).

No âmbito da Pintec, esforço inovativo refere-se à P\&D (pesquisa básica, aplicada ou desenvolvimento experimental) e a outras atividades complementares tais como aquisição de equipamentos, serviços e conhecimentos externos. Deve-se considerar que a relação de gastos com atividades inovativas sobre vendas da indústria brasileira como um todo foi em 2003, 2005 e 2011, respectivamente, de 2,5\%, 2,8\% e 4,6\% (IBGE, 2003, 2005, 2011). Quando se confrontam com os percentuais da indústria de equipamentos e materiais médico-hospitalares e odontológicos, que foram, respectivamente, de $3,1 \%, 5,3 \%$ e 3,7\%, verifica-se, com exceção de 2011 , que as empresas da indústria apresentaram taxa de inovação acima da média nacional, estando incluídas, portanto, entre as atividades de alta intensidade tecnológica, o que claramente está relacionado às características inerentes a tais ativida- 
des. Entretanto, esse dinamismo relativo situa-se muito aquém do verificado em nível mundial, não conferindo à indústria local competitividade internacional. Essa situação é claramente exemplificada pela relação entre os gastos com atividades de P\&D e as vendas. Conforme visto anteriormente, esse percentual varia de 7 a 13\% entre as empresas líderes mundiais, ao passo que para a indústria de equipamentos brasileira é de apenas 1,2\% para 2003, 2,3\% para 2005 e 1,2\% para 2011.

Em especial nos anos de 2003 a 2005, o novo aparato regulatório teve efeito positivo sobre o segmento de produtos médicos, ao induzir compulsoriamente o investimento em inovações incrementais em produtos e processos produtivos, o que de forma notória demonstra o "efeito colateral" positivo da regulação no setor de produtos médicos, que foi o de induzir compulsoriamente o investimento em inovações incrementais em produtos e processos produtivos. Contudo, apesar de catalisar a indução de atividades de inovação, a regulação não pode ser considerada como o principal drive de inovação nas empresas (Oliveira \& Button, 2012).

Além de ter estrutura bastante segmentada, a indústria congrega grande número de empresas de pequeno e médio porte, especializadas, na sua maioria, nos segmentos de baixa e média densidade tecnológica. Muitas delas têm formatos gerenciais inadequados para a competitividade, como estrutura familiar e baixo grau de profissionalização da gestão. Esses fatores ajudam a explicar o afastamento da indústria da fronteira tecnológica, em termos dos grupos de produtos, a despeito do processo de expansão observado no período recente.

Assistiu-se no Brasil a mudanças significativas a partir de 2002, no primeiro governo Lula, quando se retomou o papel do Estado de formulador de políticas e estratégias de desenvolvimento nacional. As novas orientações cristalizaram-se em um conjunto de ações governamentais que buscaram reforçar a estrutura produtiva e inovativa do tecido industrial brasileiro em geral, e das indústrias da saúde em particular.

Dentre as novas orientações, mencione-se a Política Industrial e Tecnológica e de Comércio Exterior (PITCE) do Ministério de Desenvolvimento, Indústria e Comércio Exterior de 2003, e a Política Nacional de Ciência, Tecnologia e Inovação em Saúde (PNCTIS) de 2004 e o Programa Mais Saúde (que define o complexo industrial da saúde como um dos eixos estratégicos para a política de saúde) de 2007, ambos do Ministério da Saúde. Destaca-se ainda o Programa de Aceleração do Crescimento (PAC) da Inovação de 2007, do Ministério de Ciência e Tecnologia, e a Política de Desenvolvimento Produtivo (PDP) de 2008, mais uma vez do Ministério de Desenvolvimento, Indústria e Comércio Exterior.

Paralelamente à PDP foi criado, no âmbito do Ministério da Saúde, o Grupo Executivo do Complexo Industrial da Saúde (Gecis), um fórum permanente que, envolvendo vários ministérios e instituições estratégicas para o CEIS, objetivou uma articulação entre atores do campo da política industrial e de CT\&I e da Saúde e a sociedade civil, para a proposição de ações consideradas relevantes e estratégicas para o desenvolvimento do marco regulatório de implantação da estratégia de desenvolvimento para a área da saúde (Brasil, 2008).

Entre as mais recentes ações com impactos na saúde, destacam-se o Brasil Maior, lançado em 2011, e a Estratégia Nacional de Ciência, Tecnologia e Inovação 2012-2015 (ENCTI), do Ministério da Ciência, Tecnologia e Inovação, lançada em 2012. 
O Programa Brasil Maior compreende uma nova política industrial, tecnológica, de serviços e de comércio exterior visando ao estímulo à inovação e à produção nacional para alavancar a competitividade da indústria e a geração de emprego e renda em benefício do povo brasileiro. Entre as medidas previstas, saliente-se a Lei de Compras Governamentais, que estipula uma margem de preferência de até $25 \%$ nos processos de licitação para produtos manufaturados e serviços nacionais que atendam às normas técnicas brasileiras (Brasil, 2011). Essas margens são definidas levando-se em consideração a geração de emprego e renda e o desenvolvimento e a inovação tecnológica realizados no país; abrangem remédios, produtos biológicos e equipamentos de saúde fabricados no Brasil.

A ENCTI, por sua vez, reafirma a prioridade do segmento de fármacos e do complexo produtivo e enfatiza a necessidade de promover mecanismos de estímulo à inovação em saúde e intensificar a transferência tecnológica para os laboratórios públicos nacionais (Brasil, 2012). Com a ENCTI, o Estado assume mais uma vez o seu papel no enfrentamento do desafio de redefinir e impulsionar o desenvolvimento do sistema produtivo da saúde por meio da articulação de várias instâncias da área da saúde, bem como das demais esferas de governo.

Destaque-se, no âmbito do CEIS, a indução ao estabelecimento de parcerias entre agentes públicos e privados, as designadas parcerias para o desenvolvimento produtivo (PDPs). Essa iniciativa de 2009 do Ministério da Saúde, a qual o Programa Brasil Maior de 2011 consolida como estratégia de desenvolvimento do parque produtivo e inovativo da saúde, visa à melhoria do suprimento em saúde e do acesso a medicamentos e produtos médicos (equipamentos e materiais de uso) essenciais à população, ao fortalecimento de empresas e laboratórios nacionais, à redução de dependência nas importações e, concomitantemente, à diminuição do déficit comercial.

No âmbito de produtos médicos foram realizadas 11 PDPs envolvendo 15 produtos para a saúde nos campos da hemodiálise, cardiologia, cirurgia geral, urgência e emergência, diagnóstico e monitoração, oftalmologia, kits para diagnóstico e transplante de órgãos. A Tabela 4 detalha essas PDPs, que envolvem as instituições públicas Fundação para Remédio Popular, Laboratório Farmacêutico do Rio Grande do Sul, Indústria Química do Estado de Goiás, Núcleo de Tecnologias Estratégias em Saúde da Universidade Estadual da Paraíba, Centro de Tecnologia e Geociências da Universidade Federal de Pernambuco (CTG), a parceria do Instituto de Biologia Molecular do Paraná com a Fundação Oswaldo Cruz e o Instituto Vital Brasil -, as empresas privadas nacionais Lifemed, Scitech, Opto Eletrônica e Cristália - e as empresas de capital estrangeiro Johnson \& Johnson, Medtronic, ST Electronics e IGL Group (Gadelha, 2013).

Conforme se verifica na tabela, a expectativa somente no primeiro ano era de que as compras públicas realizadas pelo Ministério da Saúde atingissem o montante de R \$ 364 milhões e o potencial de compras do SUS desses produtos correspondesse a R \$ 573 milhões. Tais compras deviam representar uma economia de divisas, ao final dos projetos, de US\$ 370 milhões ao ano (Gadelha, 2013).

No âmbito das PDPs, a transferência de tecnologia e a integração gradativa do processo produtivo são a base de sustentação para que seja firmado um compromisso de compra desses produtos pelo Ministério da Saúde. A viabilização da parceria se dá por meio da associação de pelo menos um agente público com um agente privado, que realiza o desenvolvimento e transferência de tecnologia de produção para o primeiro. 
Outro importante instrumento de política industrial recentemente criado são as chamadas medidas de compensação comercial, industrial e tecnológica. Esse importante instrumento, inserido na lei federal n. 8.666/1993, permite que, mediante prévia justificativa da administração, os editais de licitação para a contratação de bens, serviços e obras exijam que o contratado promova, em favor de órgão ou entidade integrante da administração pública, qualquer prática compensatória estabelecida como condição para o fortalecimento da produção de bens, do desenvolvimento tecnológico ou da prestação de serviços, com a intenção de gerar benefícios de natureza industrial, tecnológica ou comercial.

Tabela 4 - Parcerias para o desenvolvimento produtivo (PDPs) em equipamentos médicos. Brasil - 2013

\begin{tabular}{|c|c|c|c|}
\hline Indicação & Produto & $\begin{array}{l}\text { n. de } \\
\text { PDPs }\end{array}$ & $\begin{array}{c}\text { Compras públicas } \\
\text { Expectativa para o ano } 1 \text { (R\$ milhões) }\end{array}$ \\
\hline \multirow[t]{2}{*}{ Hemodiálise } & Dialisador & \multirow[b]{2}{*}{1} & 84,6 \\
\hline & Máquina para hemodiálise & & 82,6 \\
\hline \multirow[t]{6}{*}{ Cardiologia } & Stent coronariano & 2 & 49 \\
\hline & Stent arterial & \multirow[t]{2}{*}{1} & 2,6 \\
\hline & Cateter balão para stent arterial & & 1,4 \\
\hline & Cateter balão para stent coronário & & 9,8 \\
\hline & Marca-passo câmara única & \multirow[b]{2}{*}{1} & 6,3 \\
\hline & Marca-passo câmara dupla & & 25,3 \\
\hline \multirow[t]{2}{*}{ Cirurgia geral } & Grampeador cirúrgico & \multirow[t]{2}{*}{1} & 1,4 \\
\hline & Cargas para grampeador cirúrgico & & 0,5 \\
\hline $\begin{array}{l}\text { Urgência e } \\
\text { emergência }\end{array}$ & Desfibrilador/cardioversor & 1 & 29,5 \\
\hline $\begin{array}{l}\text { Diagnóstico e } \\
\text { monitoração }\end{array}$ & Monitor multiparâmetros & 1 & 35,1 \\
\hline Oftalmologia & $\begin{array}{l}\text { Conjunto oftalmológico para diagnóstico } \\
\text { e tratamento de cegueiras evitáveis } \\
\text { composto de nove equipamentos: } \\
\text { 1. Microscópio } \\
\text { 2. Autorrefrator com mesa } \\
\text { 3. Retinógrafo não midriático } \\
\text { 4. Autoprojetores tipo Magis Nano } \\
\text { 5. Oftalmoscópios binoculares indiretos } \\
\text { 6. Greens } \\
\text { 7. Cadeiras com coluna oftálmica } \\
\text { 8. Lâmpada de fenda (LF) tonômetro } \\
\text { 9. Laser verde com LF e mesa }\end{array}$ & 1 & 23,9 \\
\hline $\begin{array}{l}\text { Kits para } \\
\text { diagnóstico }\end{array}$ & $\begin{array}{l}\text { Plataforma multiteste para detecção de } \\
\text { sepse }\end{array}$ & 1 & $\mathrm{P} \& \mathrm{D}$ \\
\hline $\begin{array}{l}\text { Transplante de } \\
\text { órgãos }\end{array}$ & $\begin{array}{l}\text { Solução para preservação de órgãos para } \\
\text { transplantes }\end{array}$ & 1 & 12,3 \\
\hline $\begin{array}{l}\text { Total } \\
\text { Total potencial }\end{array}$ & o SUS & & $\begin{array}{l}364,3 \\
573,0\end{array}$ \\
\hline
\end{tabular}

Fonte: Gadelha, 2013. 
A Saúde foi a primeira pasta a utilizar esse instrumento na aquisição de equipamentos para tratamento do câncer (aceleradores lineares). No certame promovido pelo Ministério da Saúde, a centralização das compras permitiu um deságio de 60\% sobre o preço de referência; além disso, o edital previa a obrigação da contratada de instalar no Brasil uma fábrica de aceleradores lineares (Paula, 2014).

O grande objetivo do estabelecimento das PDPs é o fomento ao desenvolvimento endógeno da capacidade produtiva e de inovação da indústria nacional, com a concomitante redução de dependência externa e o aproveitamento da oportunidade de uma demanda crescente e vigorosa em saúde.

Nesse processo, destaca-se o papel do Estado no fortalecimento e ampliação das vantagens competitivas da indústria nacional. De acordo com o Instituto de Estudos e Marketing Industrial (Iemi, 2010), o poder público era responsável por 21,5\% das compras da indústria em 2009; todavia, como ressaltam Pieroni, Reis e Souza (2010), parte significativa das compras de entidades privadas é reembolsada pelo sistema público de saúde, o que, na prática, aponta para uma demanda próxima de 50\% dos produtos vendidos pela indústria. Assim, o Estado, por seu papel de grande consumidor de bens e serviços, pode, valendo-se do seu poder de compra, direcionar o desenvolvimento produtivo e inovativo da indústria.

Nessa direção, o Ministério da Saúde, por meio da portaria n. 3.089 de 2013, identificou um conjunto de equipamentos e materiais de consumo prioritários no âmbito do SUS como itens que deveriam receber apoio em termos do adensamento tecnológico envolvido. ${ }^{4}$ Essa listagem, elaborada pelo Ministério da Saúde e sancionada pelo Gecis, tendo como critérios para a seleção desses produtos as demandas tecnológicas do SUS, a dependência tecnológica e o déficit na balança comercial, orienta as ações estratégicas do ministério referentes ao CEIS no que tange às PDPs, à centralização de compras, à incorporação tecnológica e a encomendas tecnológicas.

Nesse sentido, Gadelha e colaboradores (2012) notam que o uso do poder de compra do Estado orientado para a inovação reside em seu potencial de articular a demanda para alcançar objetivos relacionados ao desenvolvimento nacional, a exemplo da sinalização para o setor privado das necessidades públicas, que estimula o desenvolvimento de soluções inovadoras para o perfil de demanda da sociedade. O uso de poder de compra é uma política emblemática para o desenvolvimento da base de CT\&I em saúde, tendo em vista a complexidade que envolve a orientação de trajetórias tecnológicas que sejam, a um só tempo, economicamente competitivas e socialmente inclusivas.

\section{Tendências}

O mercado mundial de equipamentos médicos dobrou na última década, e a expectativa é de um elevado crescimento, sobretudo nos países emergentes, que devem exibir taxas de 15\% a. a. nos próximos cinco anos em razão das mudanças demográficas e epidemiológicas em curso, o que tem promovido a ampliação da demanda por serviços de saúde (Landim et al., 2013).

\footnotetext{
${ }^{4}$ A atual portaria revoga as duas anteriores, quais sejam, a n. 978, de maio de 2008, e a n. 1.284, de 2010, mantendo no seu conteúdo os produtos nelas identificados.
} 
Prevê-se que o mercado mundial para essa indústria atinja o valor de US\$ 455 bilhões em 2018 (Worldwide Medical..., 2013). O Gráfico 4 apresenta para esse ano a participação dos maiores mercados mundiais.

As estimativas indicam que os EUA continuem representando o maior mercado mundial no final da década, embora sua participação relativa apresente tendência decrescente (em 2008, os EUA detinham 40,7\% do mercado mundial). As principais mudanças ficam por conta da crescente importância dos maiores mercados dos países designados Brics, tanto em tamanho absoluto quanto em participação relativa: Brasil, Rússia, Índia e China. A título de exemplo, Canadá, Suíça e Espanha, que em 2008 figuravam entre os dez maiores mercados mundiais dessa indústria, já em 2013 foram substituídos pelas quatro economias emergentes (Gadelha et al., 2012). O Gráfico 5 apresenta a evolução de 2009 a 2018 da participação dos Brics no mercado mundial, em termos percentuais.

Gráfico 4 - Distribuição dos dez maiores mercados mundiais - 2018 (em \%)

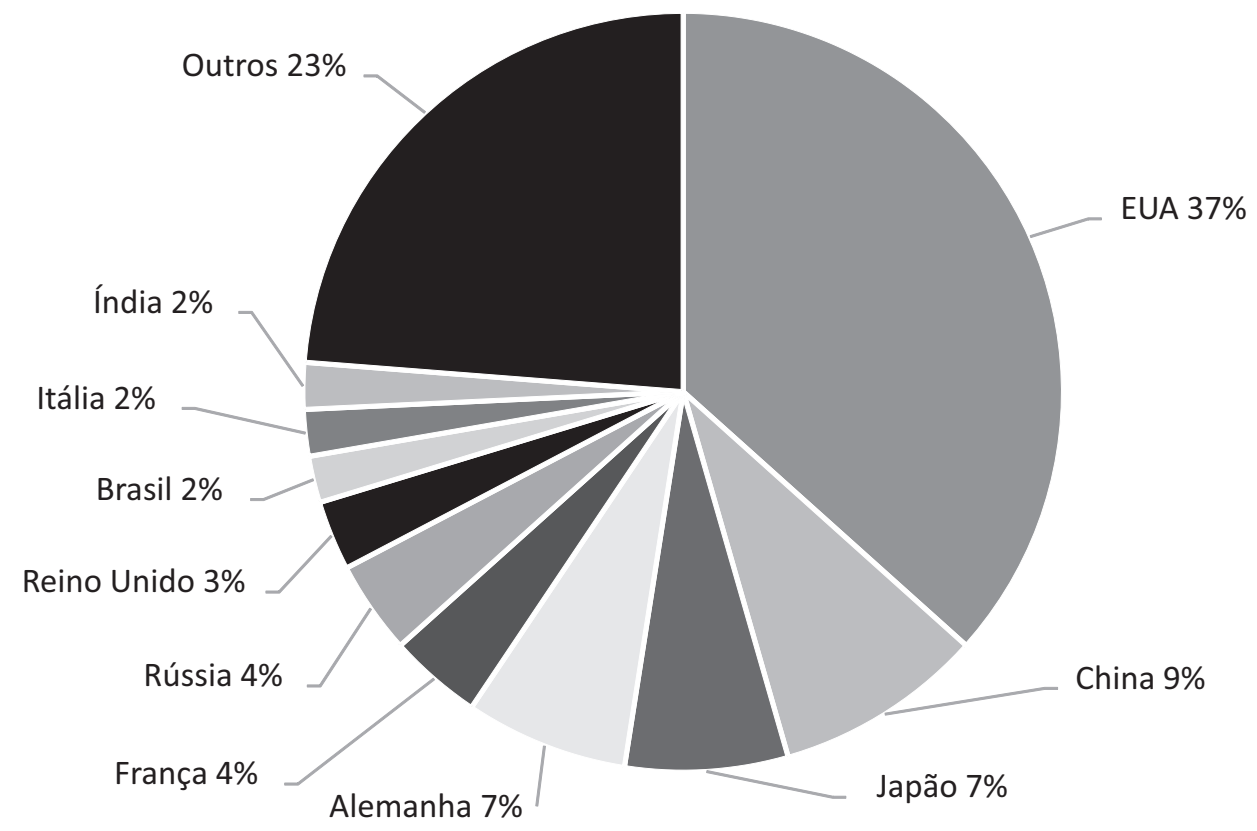

Fonte: Worldwide Medical Market Forecasts to 2018, 2013.

Embora o crescimento da China se destaque em relação aos demais países, a participação dos quatro maiores países do Brics representa uma variação de praticamente $200 \%$ de 2009 a 2018 . Em 2009, esses países participavam com 7\%, em 2013 esse percentual era de 10,4\% e a perspectiva para 2018 é de que os quatro mercados juntos representem 15,8\% do mercado mundial para essa indústria. Em termos de ranking mundial em 2018, o mercado chinês será o segundo maior mercado, a Rússia estará na sétima posição, o Brasil na oitava e a Índia na décima (Worldwide Medical..., 2013). 
Gráfico 5 - Evolução da participação dos maiores mercados do Brics no mercado mundial - 2009$2018(\mathrm{em} \%)$

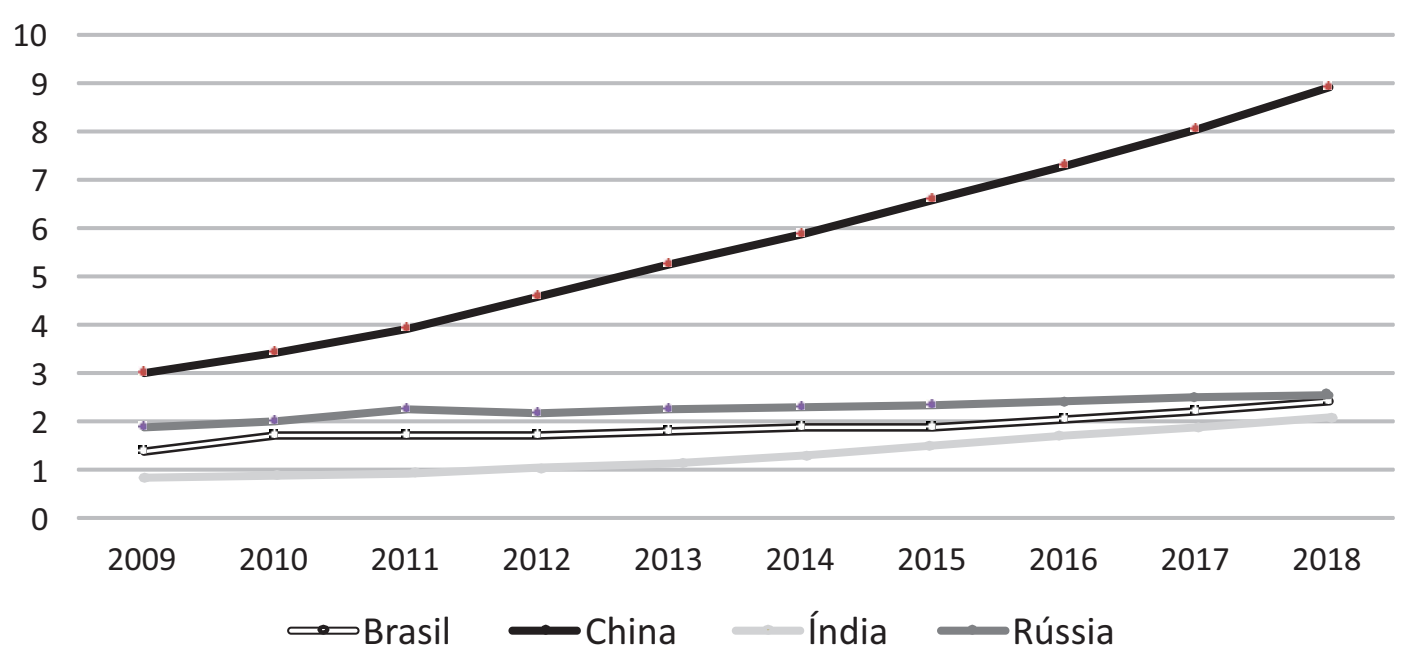

Fonte: Worldwide Medical Market Forecasts to 2018, 2013.

Mudanças demográficas e epidemiológicas, ampliação da demanda por serviços de saúde, reformulação dos sistemas de saúde, aumento dos gastos em saúde, população urbanizada com crescente poder de compra, dinamismo econômico e perspectivas de crescimento são considerados as principais razões para a ampliação da participação dos Brics no mercado mundial.

De acordo com as perspectivas, o Brasil deverá ser em 2018 o oitavo maior mercado mundial de equipamentos médicos, com um valor de vendas de US\$10.981 milhões (Worldwide Medical..., 2013).

Em que pese a fragilidade relativa da indústria nacional de equipamentos médicos, há um importante parque industrial específico instalado; o mercado brasileiro ocupava, já em 2013, a décima posição no ranking mundial, e o Brasil é praticamente o único país na América do Sul e Central dotado de uma indústria relativamente completa de fabricação de equipamentos e materiais médico-hospitalares e odontológicos

Apesar de se constituir em um oligopólio diferenciado, com predomínio de grandes empresas multinacionais, a indústria mundial comporta, até por sua característica de heterogeneidade tecnológica, diversos nichos competitivos que se configuram em oportunidades para empresas de diversas especialidades e diferentes portes. A identificação desses nichos para a indústria brasileira relativamente a equipamentos médico-hospitalares, implantes e odontologia é o tema da próxima seção.

\section{Equipamentos médico-hospitalares}

O segmento de equipamentos médico-hospitalares compreende empresas fabricantes de:

1) Mobiliário: camas, carros, mesas, estantes, poltronas, armários etc.;

2) Eletromédicos: mesa cirúrgica, cama, bisturi, incubadora, aparelhos de anestesia, ventiladores, monitor cardíaco, autoclaves, respiradores, eletrocardiógrafo, lâmpada cirúrgica, 
bomba de infusão, equipamentos para hemodiálise, endoscópios, aparelhos para tomografia computadorizada e para diagnóstico por ressonância magnética etc.;

3) Instrumental cirúrgico: pinças, tesouras, cabo bisturi, fórceps, afastadores etc.;

4) Equipamentos fisioterápicos: barras, andadores, aparelhos de ultrassom e de ondas curtas, turbilhão, banho de parafina etc.;

5) Hotelaria: máquinas de lavar, calandra, centrifugadoras, esterilizadores, cozinha etc. (Iemi, 2010)

Os equipamentos eletromédicos são os de maior intensidade tecnológica e compreendem ampla gama de equipamentos e dispositivos cuja base técnica é a eletroeletrônica. Dentre os produtos, destacam-se marca-passo cardíaco, desfibrilador e cardioversor, ventilador pulmonar, mesa cirúrgica, máquinas de hemodiálise, incubadoras, aparelhos de ultrassom, equipamentos de monitoração etc. (ABDI, 2009).

Nesse segmento, portanto, a heterogeneidade tecnológica característica da indústria de equipamentos e materiais médico-hospitalares e odontológicos encontra todo o seu significado. Abarcando diversas áreas como cuidados intensivos, neonatologia, hemodiálise, equipamentos médico-cirúrgicos, entre outras, a competição se dá em termos de segmentos de mercado. Em cuidados intensivos, por exemplo, o mercado mundial era de US $\$ 47$ bilhões em 2011, e 80\% desse mercado eram dominados por três empresas: GE, Drager e Philips (Landim et al., 2013). Em equipamentos de monitoração, os principais fabricantes mundiais são a ArtemaMEC, Biocare, Card Guard Scientific Survival, Criticare Systems, Datascope, Datex, Drager e GE. Em equipamentos utilizados em processos cirúrgicos, destacam-se a ACMI, Asap, Fujinon, Karl Storz, Olympus, Pentax, Richard Wolf e Stryker (ABDI, 2009).

Nessa área, o desenvolvimento de novos produtos carece da integração de diferentes tecnologias crescentemente baseadas em conhecimentos multidisciplinares, como design de produto, desenvolvimento de softwares de controle e componentes mecânicos e eletrônicos (Landim et al., 2013). Até mesmo as grandes corporações têm dificuldade em incorporar os vastos domínios científicos e tecnológicos necessários ao desenvolvimento de novos produtos, o que transforma a empresa de equipamentos médicos em um agente agregador de insumos, tecnologias e know-how de diferentes fontes em um único equipamento (Pieroni, Reis \& Souza, 2010). Isso leva à necessidade de expansão de acordos de cooperação e crescente ampliação de redes industriais intersetoriais, especialmente no que tange à cadeia de fornecedores. Ao mesmo tempo, esse modelo permite que empresas menores ocupem nichos de mercado, como é o caso das empresas nacionais, já que não é necessário deter todas as competências do processo produtivo.

Simultaneamente, as grandes empresas que estabelecem o padrão e o ritmo de incorporação tecnológica da indústria têm, crescentemente, adotado estratégias de integração de suas atividades industriais e comerciais mediante o estabelecimento da oferta de soluções integradas, isto é, produtos associados a serviços: rede de prestação de serviços técnicos, de assistência e manutenção, programas de software e serviços financeiros. O uso desses equipamentos está, de modo geral, associado à necessidade de reposição de insumos, de peças ou de produtos químicos, o que, ao reforçar os custos de mudança, também gera uma dependência prolongada entre fornecedores e consumidores. 
Marca, reputação, confiança e qualidade dos produtos e serviços são outros ativos complementares que promovem a fidelização dos usuários. Tais estratégias têm significado um aumento das barreiras à entrada nos segmentos em que as grandes empresas atuam, impedindo ou mesmo excluindo as empresas de menor porte que dispõem de menos recursos (Gadelha et al., 2012).

No Brasil, o segmento de equipamentos médico-hospitalares foi responsável, em termos do valor da produção, por R\$ 2,2 bilhões (ver Gráfico 2) em 2012, o que correspondeu a cerca de 46\% do total da indústria de equipamentos e materiais médico-hospitalares e odontológicos.

Esse segmento conta com um parque produtivo diversificado, com cerca de duas centenas de empresas operando no país, sendo 192 delas associadas à Abimo (Abimo, 2014). Por exemplo, os principais fabricantes nacionais de equipamentos utilizados em processos cirúrgicos são a H. Strattner e a Komlux. Em equipamentos de monitoração destaquem-se Anamed, Braile, CMOS Drake, Dixtal, Intermed, Instramed, JG Moriya, Omnimed, Protec, TEB, Transform, Transmai e Ventura (ABDI, 2009).

Relativamente ao comércio exterior, o segmento de equipamentos médico-hospitalares foi responsável por, respectivamente, 19,5\% e 10,3\% das importações e exportações do total da indústria de equipamentos e materiais médico-hospitalares e odontológicos em 2013. Entre 2009 e 2013 o segmento apresentou um crescimento de $67 \%$ nas exportações, com destaque para incubadoras de recém-nascidos, e de apenas 25\% nas importações (Brazilian Health Devices, 2014), concentrando-se em aparelhos e instrumentos para medicina. Todavia, apesar de em termos relativos as exportações terem apresentado um crescimento superior ao das importações, em valores absolutos registrou-se um déficit na balança comercial de US\$ 913 milhões em 2013, conforme mostrado na Tabela 5, que apresenta a evolução de tal déficit de 2009 a 2013.

Tabela 5 - Evolução do déficit comercial do segmento de equipamentos médico-hospitalares. Brasil 2009-2013(em US\$ milhões)

\begin{tabular}{|c|c|c|c|c|c|}
\hline & 2009 & 2010 & 2011 & 2012 & 2013 \\
\hline Equipamentos & $-393,3$ & $-678,9$ & $-612,5$ & $-797,7$ & $-913,5$ \\
\hline Outros segmentos & $-1.838,4$ & $-2.355,1$ & $-2.746,7$ & $-2.937,7$ & $-3.249,9$ \\
\hline $\begin{array}{l}\text { Total da indústria } \\
\text { de equipamentos } \\
\text { médicos }\end{array}$ & $-2.231,7$ & $-3.034,0$ & $-3.359,2$ & $-3.735,4$ & $-4.163,4$ \\
\hline
\end{tabular}

Fonte: Brazilian Health Devices, 2014.

Em que pese esse comportamento no que tange ao comércio exterior, pode-se considerar que o segmento de equipamentos médico-hospitalares apresenta um dinamismo significativo, atestado pelas taxas de crescimento dos últimos anos, pelo atendimento da demanda interna, por exportações sustentáveis e por maior conteúdo tecnológico relativo(por exemplo, monitores de sinais vitais multiparamétricos, ventiladores pulmonares, incubadoras para recém-nascidos, berços radiantes, equipamentos de fototerapia, esterilizadores médico-cirúrgicos, bombas de infusão, bisturis elétricos, equipamentos de mecanoterapia e fisioterapia, mesas cirúrgicas, focos cirúrgicos e camas 
hospitalares elétricas). Os fabricantes desse segmento representam uma parcela significativa da produção nacional, inovam frequentemente suas linhas de produtos e alcançaram, nos últimos anos, presença relevante no mercado internacional (ABDI, 2009).

A título de exemplo, salientem-se incubadoras para recém-nascidos. Empresas como Fanem, Olidef e Gigante já ocupam posição de relativo destaque e exportam para algumas dezenas de países. Em 2013, o Brasil exportou mais de US\$ 10 milhões em incubadoras para bebês (GIS, 2014), segmento que apresenta potencial de crescimento significativo, inclusive exportador, tendo grande importância para o SUS no que diz respeito aos impactos nas taxas de mortalidade infantil. O fortalecimento da expansão da competitividade internacional, mediante ênfase na inovação e lançamento de novos produtos, é fundamental em equipamentos de neonatologia.

Em sentido oposto, ressaltem-se os sistemas de hemodiálise, que são formados pelas máquinas (equipamentos) e pelos descartáveis; estes incluem o hemodialisador, que é o filtro, elemento essencial e de maior valor agregado em todo o sistema. No caso de hemodialisadores de alta densidade tecnológica não existe produção nacional. O SUS gasta em torno de R $\$ 2,5$ bilhões com terapia renal substituta, sendo que $75 \%$ desse montante referem-se à aquisição de filtros hemodialisadores. O tratamento da hemodiálise é integralmente realizado pela saúde pública, que atende cerca de oitenta mil pacientes por ano. O uso do poder de compra do Estado poderá viabilizar a produção nacional em curto período, ao mesmo tempo que ensejaria condições para que o SUS beneficie um maior número de pacientes, já que atualmente apenas um terço da demanda é atendido (Landim et al., 2013). Essa área representa uma oportunidade a médio prazo; equipamentos de hemodiálise estão incluídos na portaria n. 3.089 de 2013 e são objeto das PDPs.

A longo prazo, os principais elementos no campo da saúde que terão influência no comportamento da indústria de equipamentos médicos referem-se a pressões por redução de custos, medicina preventiva, telemedicina, atenção domiciliar e crescente incorporação de novas tecnologias.

O envelhecimento da população e a ampliação dos serviços de saúde no sentido da universalização e da integralização são dois elementos que, conjugados, deverão exercer forte pressão sobre os gastos públicos e privados com a saúde. Nesse cenário, a indústria de equipamentos deverá sofrer fortes e crescentes pressões para que seus desenvolvimentos tecnológicos levem ao aumento não somente da qualidade dos padrões de tratamento e diagnóstico, no intuito de serem mais efetivos, mais rápidos, mais seguros e menos invasivos para uma grande variedade de doenças, mas também da sua capacidade de reduzir o custo dos tratamentos (Gadelha et al., 2012).

Em um quadro geral de ampliação de serviços de saúde e seus custos, dever-se-á dar importância crescente à medicina preventiva, isto é, ao diagnóstico precoce. Os serviços de saúde em geral e os equipamentos neles utilizados deverão responder ao caráter cada vez mais preventivo dos atendimentos, reduzindo tempos de internação e de recuperação, custos e, concomitantemente, a taxa de prestação de serviços.

A monitoração de parâmetros fisiológicos e sinais vitais de pacientes é utilizada em quase todos os procedimentos médicos e hospitalares, incluindo cirurgias, processos de recuperação, terapias específicas e diagnósticos. Entre os equipamentos relacionados ao monitoramento do paciente incluem-se 
monitores, aparelhos de ventilação, aparelhos de anestesia e bombas de infusão. Tendências no Brasil no que tange ao envelhecimento populacional e a mudanças no perfil epidemiológico, com o predomínio de doenças crônico-degenerativas, associadas à crescente importância de medicina preventiva e atendimento domiciliar, fazem desta uma área de suma importância. O Brasil tem competência razoável, no entanto os fabricantes nacionais produzem equipamentos específicos, ao passo que a tendência mundial é a oferta de soluções integradas (Pieroni, Reis \& Souza, 2010). Fortalecimento das competências tecnológicas das empresas, que lhes permita o desenvolvimento de novos produtos, consolidação patrimonial e uso do poder de compra do Estado (vários desses equipamentos estão incluídos na portaria n. 3.089, de 2013, e são objeto das PDPs) estão entre as medidas a serem adotadas para a ampliação das vantagens competitivas das empresas nacionais.

Uma das tendências no campo das tecnologias de monitoração, por exemplo, é o desenvolvimento de moléculas com capacidade de se reconhecerem mutuamente, que podem viabilizar novos sensores químicos e biossensores para uso em equipamentos como capinógrafos (monitoramento do dióxido de carbono), oximetria (medição do nível de oxigênio), detectores de nível de glicose e pressão sanguínea. Pelo tamanho e dimensão desses sensores será possível colocá-los dentro do paciente de forma que transmitam, por meio de pequenos dispositivos de comunicação eletrônica, dados nele coletados. A grande vantagem dessas tecnologias será a de disponibilizar a monitoração, em tempo real, de parâmetros biológicos e bioquímicos do paciente (Gadelha et al., 2012).

Telemedicina compreende a oferta de serviços ligados aos cuidados com a saúde, nos casos em que a distância é um fator crucial; tais serviços são prestados por profissionais da área da saúde, usando tecnologias de informação e de comunicação para o intercâmbio de informações válidas para diagnósticos, prevenção e tratamento de doenças e a contínua educação de prestadores de serviços em saúde, assim como para fins de pesquisa e avaliação. Outrossim, equipamentos médicos de alto custo de aquisição e de manutenção poderão se concentrar em locais estratégicos e conectados em rede a uma série de usuários. Abre-se, assim, uma área de grande potencial, que é o campo de equipamentos de baixo custo, com o aproveitamento, por exemplo, das potencialidades dos microcomputadores (Gadelha et al., 2012).

A atenção domiciliar, viabilizada pelas TICs, é uma modalidade de cuidado com a saúde na qual o paciente pode tratar da sua doença em casa junto da família, o que possibilita uma recuperação mais rápida. A atenção domiciliar constitui uma estratégia de desospitalização e é uma das áreas na qual se prevê um forte crescimento. Essa modalidade, que deverá crescer em razão do envelhecimento da população e da necessidade de humanização do atendimento, bem como da economia de recursos gerada e da redução do tempo de internação, abre amplas oportunidades para equipamentos eletroportáteis. Tais condições forçarão as empresas a buscar alternativas que resultem em equipamentos dotados de portabilidade, conectividade e segurança para que possam ser operados por não especialistas. Monitores de glicose, dispositivos para aplicação de insulina, nebulizadores e concentradores de oxigênio são exemplos de equipamentos que se enquadram nessa categoria (Gadelha et al., 2012).

Outra tendência em equipamentos de monitoramento é a crescente incorporação das TICs. Essas tecnologias viabilizam o monitoramento remoto e geram potencial para redução do tempo de internação e para solução da escassez de profissionais, o que estimula a redução de custos 
(Landim et al., 2013). Entre as principais tendências, ressalte-se a informática na saúde, que compreende o armazenamento, a recuperação e o uso da informação, de dados e conhecimentos biomédicos para a resolução de problemas e tomada de decisão; a bioinformática, que é o estudo da aplicação de técnicas computacionais e matemáticas à geração e gerenciamento de (bio)informação; e a engenharia biomédica, que cuida da concepção de equipamentos médicos, biomédicos e odontológicos voltados para diagnóstico ou tratamento terapêutico (ABDI, 2010).

No âmbito dos chips dedicados à indústria de equipamentos médico-hospitalares, por exemplo, que podem ser utilizados em inúmeros equipamentos eletromédicos, deve-se ressaltar que, atualmente, todos os equipamentos eletromédicos utilizam placas eletrônicas e chips de prateleira, ou seja, componentes genéricos que, para cumprir uma função específica, demandam diferentes níveis de softwares. Os chips dedicados, considerados de alta densidade tecnológica, são projetados para cumprir funções específicas e não dependem de programação. Com isso agregam inúmeras vantagens, como, por exemplo: apresentam maior confiabilidade no funcionamento; não demandam a elaboração de programação específica, que é de alto custo, e por isso têm seu funcionamento simplificado; são de fácil manutenção; o chip dificilmente apresenta problema, e quando apresenta é de fácil substituição; representam amplos ganhos de escala. Embora o chip exija um grande investimento na sua concepção, este pode ser diluído por um número infinito de unidades, o que acaba por reduzir o custo do equipamento (Gadelha et al., 2012).

No caso de equipamentos médicos fundamentados em ótica - endoscópios e similares -, os produtos locais apresentam poucos desenvolvimentos, sobretudo em processamento de imagens. Como os produtores locais têm pouca capacitação, sobretudo em produtos mais intensivos em tecnologia, a demanda nacional é atendida via importações, o que tem gerado um déficit na balança comercial - em 2013, por exemplo, as importações com endoscópios totalizaram cerca de US\$ 40 milhões (GIS, 2014). As grandes oportunidades nessa área se referem à consolidação dos procedimentos médicos de videolaparoscopia, que contam com uma forte cobertura do SUS, e de aplicações para inúmeras áreas da medicina nas quais a tônica é a convergência tecnológica entre a área médica e as tecnologias de imagem.

Note-se que diversas modalidades diagnósticas utilizam sistemas de imagens digitais. Um sistema de informação hospitalar contém as mais diversas informações digitais e, em função da tecnologia empregada, as imagens médicas são consideradas como um sistema à parte, organizadas em um sistema de transmissão e arquivamento de imagens médicas chamado PACS (picture archiving and communication system).

O PACS é um sistema que proporciona o armazenamento e a comunicação de imagens geradas por equipamentos médicos, possibilitando que as informações dos pacientes e suas respectivas imagens sejam compartilhadas e visualizadas em monitores de alta resolução, distribuídos em locais fisicamente distintos. Essa tecnologia proporciona inúmeras vantagens, nomeadamente em telemedicina no que tange ao envio de imagens e informações de pacientes para polos especializados, e no ensino e pesquisa, pois viabiliza a criação de uma biblioteca digital de imagens médicas que podem ser compartilhadas (Oftalmologia, 2014).

Ainda no âmbito das novas tecnologias crescentemente incorporadas em equipamentos médicos, saliente-se a automação. Cada vez mais os novos desenvolvimentos focam equipamentos projetados 
para operações automatizadas, complexas e de precisão. Esses equipamentos podem executar uma variedade de operações, incluindo a montagem de dispositivos médicos e de preparação de receitas, automação de laboratórios, maquinário de monitoração, manuseio de materiais, embalagem e montagem eletrônica (Medical..., 2010).

A cirurgia robótica é um tipo de cirurgia minimamente invasivo em que são usados dispositivos robotizados controlados pelo cirurgião. Apesar de os primeiros passos terem sido dados no fim dos anos 1980, aperfeiçoamentos tecnológicos posteriores, sobretudo no que tange a técnicas operatórias, têm permitido expandir as áreas de aplicação da cirurgia robótica. Uma delas é a telecirurgia, isto é, cirurgia a distância (Hospital da Luz, 2014). Em um país de dimensões continentais como o Brasil, essa é uma área que apresenta francas oportunidades de desenvolvimento.

A intensificação das pressões para a redução dos custos dos sistemas de saúde, uma vez que estes precisam incorporar parcelas cada vez maiores da população, que crescentemente se torna mais longeva, e o caráter cada vez mais preventivo da medicina, reduzindo tempos de internação e recuperação, têm estimulado o desenvolvimento de novas tecnologias que possibilitem processos de recuperação nas próprias residências, apoiados pelo desenvolvimento da telemedicina. Nesse contexto, o incentivo a novos procedimentos clínicos minimamente invasivos e menos agressivos, a personalização do atendimento e a monitoração remota potencializam a miniaturização e o desenvolvimento de dispositivos inteligentes, privilegiando a convergência entre diferentes campos do conhecimento como as TICs, a nanotecnologia, a eletrônica embarcada, a microeletrônica, a engenharia de software, a mecânica fina e os novos materiais. Tal sinergia viabilizará o alcance de benefícios clínicos sem precedentes (Gadelha et al., 2012).

\section{Implantes}

Implante é um dispositivo médico feito para substituir ou atuar como uma estrutura biológica ausente do corpo. Quanto ao uso, existem implantes ortopédicos (próteses de quadril, joelho, úmero, membro, implantes para coluna, buco-maxilares, placas e parafusos etc.), cardíacos (marca-passo, desfibrilador, válvula, stent, cateter etc.), neurológicos (válvula, cateter etc.) e outros (implantes cocleares, de mama etc.).

Em termos mundiais, esse segmento é fortemente concentrado; nele predominam empresas norte-americanas com atuação global, com participações distintas em cada especialidade. Em 2012, o mercado mundial de implantes ortopédicos era avaliado em cerca de US\$ 31 bilhões, com crescimento médio esperado de $8 \%$ a. a., e o de implantes cardiovasculares em US\$ 85 bilhões, com crescimento médio esperado de 5\% a. a. (BNDES, 2013).

No Brasil, o mercado de implantes é regulado pela legislação sanitária e suprido pela oferta de fabricantes nacionais e por produtos importados. O controle sanitário é exercido, desde 1999, pelo Sistema Nacional de Vigilância Sanitária, cabendo à Anvisa a sua coordenação, incluindo a concessão de registros dos produtos comercializados e respectiva fiscalização sanitária.

No que concerne aos fabricantes nacionais, o parque é, atualmente, constituído por algumas dezenas de empresas, 62 delas associadas à Abimo, em sua maioria concentradas no estado de São 
Paulo (Abimo, 2014). Suas atividades dividem-se entre os seguintes segmentos de implantação: artroplastia; buco-maxilo; coluna e osteossíntese (traumatologia) (Neto, 2007).

Em 2012, o mercado nacional de implantes ortopédicos era avaliado em R \$ 1,1 bilhão. As projeções indicam um crescimento médio esperado de 15\% para os próximos anos; o perfil demográfico e epidemiológico do país e a ampliação de cobertura do SUS são mencionados como as principais razões para esse comportamento (BNDES, 2013).

O mercado nacional de implantes ortopédicos é extremamente concentrado: em 2010 as sete maiores empresas detinham 60\% de participação, conforme é apresentado na Tabela 6.

Em 2012, o mercado nacional de implantes cardiovasculares foi de R\$ 1,2 bilhão, e as projeções são de um crescimento médio esperado de 6\% para os próximos anos em função de doenças do coração, que já são a principal causa de morte no Brasil (BNDES, 2013).

Estrutura oligopólica e forte concentração também caracterizam o mercado de implantes cardiovasculares no país. A Tabela 7 apresenta as maiores empresas de dispositivos cardiovasculares atuantes no Brasil em 2009.

Tabela 6 - Brasil: maiores fabricantes de implantes ortopédicos - 2010

\begin{tabular}{|c|c|c|}
\hline Empresa & País & Participação (\%) \\
\hline B. Braun/Aesculap & EUA & 13,9 \\
\hline Medtronic & EUA & 10,5 \\
\hline Stryker & EUA & 10,2 \\
\hline Synthes & EUA/Suíça & 6,9 \\
\hline MDT & Brasil & 6,7 \\
\hline Depuy & EUA & 6,4 \\
\hline Baumer & Brasil & 6,0 \\
\hline Total & & 60,6 \\
\hline
\end{tabular}

Fonte: Landim et al., 2013.

Tabela 7 - Brasil: maiores fabricantes de dispositivos cardiovasculares - 2009

\begin{tabular}{l|c|c|}
\hline \multicolumn{1}{c}{ Empresa } & País & Participação (\%) \\
\hline Medtronic & EUA & 18,0 \\
\hline Boston Scientific & EUA & 17,0 \\
\hline Str. Jude Medical & EUA & 9,0 \\
\hline Cordis & EUA & 9,0 \\
Terumo & Japão & 6,0 \\
Abbot & EUA & 5,0 \\
Sorin & Itália & 4,0 \\
Total & & 68,0 \\
\hline
\end{tabular}

Fonte: Landim et al., 2013. 
Em termos gerais, o mercado nacional de implantes é dominado por importações com pequena participação de produtos nacionais. Além de sua dependência externa em produtos acabados, o país também importa matérias-primas, tais como componentes eletrônicos e ligas especiais de uso médico (Landim et al., 2013). A Tabela 8 apresenta a evolução, de 2009 a 2012, do déficit comercial do segmento de implantes, bem como o total da indústria de equipamentos médicos.

Tabela 8 - Evolução do déficit comercial do segmento de implantes. Brasil - 2009-2013 (US\$ milhões)

\begin{tabular}{|l|c|c|c|c|c|}
\hline & 2009 & 2010 & 2011 & 2012 & \multicolumn{1}{c|}{2013} \\
\hline Implantes & $-358,2$ & $-446,9$ & $-505,9$ & $-597,5$ & $-587,9$ \\
\hline Outros segmentos & $1.873,5$ & $2.587,1$ & $2.853,3$ & $3.137,9$ & $3.575,5$ \\
\hline $\begin{array}{l}\text { Total da indústria de } \\
\text { equipamentos médicos }\end{array}$ & $-2.231,7$ & $-3.034,0$ & $-3.359,2$ & $-3.735,4$ & $-4.163,4$ \\
\hline
\end{tabular}

Fonte: Brazilian Health Devices, 2014.

Em 2013, o déficit comercial com implantes foi de US\$ 588 milhões, o que representa um aumento de mais de $160 \%$ em relação a 2009. Essa situação claramente atesta a fragilidade da capacidade inovativa e produtiva da indústria nacional e a necessidade de se identificar nichos de mercado nos quais seja possível construir vantagens competitivas.

Em implantes ortopédicos, é recorrente a menção a duas áreas que carecem de desenvolvimentos tecnológicos do ponto de vista nacional: materiais e instrumentos.

Os materiais utilizados na substituição de ossos enquadram-se em uma classe denominada biomateriais e devem apresentar propriedades físicas e biológicas compatíveis com os tecidos vivos hospedeiros, propriedades que caracterizam a biocompatibilidade. O conhecimento sobre os fatores que determinam a biocompatibilidade de um material pode contribuir significativamente para desvendar os mecanismos de interação entre o tecido vivo e o implante, possibilitando o desenvolvimento e aumento da vida útil dos biomateriais, como também criar as bases para a escolha de materiais adequados para cada caso. Os materiais sintéticos utilizados para esses fins, e sobre os quais incidem as maiores pesquisas que visam a ampliar a resistência ao desgaste e ao impacto, podem ser metais, polímeros, compósitos, cerâmicas e vidros (Kawachi et al., 2000).

Sugerem-se ainda desenvolvimentos na área de projeto e fabricação de novos componentes em polímeros bioabsorvíveis para uso como implantes temporários visando a diminuir os efeitos nocivos relacionados ao uso de materiais metálicos.

Grandes instrumentos resistentes e, normalmente, perfurocortantes - tais como rugina, cinzel, osteótomos, goiva, martelos e curetas - são necessários nos procedimentos ortopédicos. Instrumentos delicados também são utilizados; os instrumentos necessários para dividir, retrair, levantar e reparar os tecidos leves das estruturas ósseas são menores e mais leves. Entre estes, incluem-se os osteótomos, o cinzel, a goiva e as curetas (Nasce, 2014).

No campo dos instrumentos sugere-se o aprimoramento de tecnologias de projeto e fabricação de ferramental cirúrgico visando a aumentar sua vida útil mantendo-se a qualidade e precisão de corte, de modo a tornar a implantação cirúrgica mais simples e segura. 
Em implantes cardiovasculares, despontam algumas tendências que carecem de desenvolvimentos: ${ }^{5}$

1) revestimento de stents metálicos com polímeros e/ou fármacos com função antineoplasia, antiproliferação ou fatores de crescimento, entre outros, para minimizar a reestenose em casos clínicos específicos;

2) polímeros bioabsorvíveis (PLA, PGA, PCL, entre outros) funcionalizados, ou não, com fármacos de ação antiplaquetária para diminuir os efeitos indesejáveis relacionados à utilização de stents metálicos;

3) descelularizaçao e recelularização de membranas xenógenas para reduzir inconvenientes associados às próteses mecânicas;

4) liga com memória de forma, como a nitinol, para expandir o stent sem balão, reduzindo os inconvenientes do uso do balão;

5) dispositivos com microeletrônica embarcada, como marca-passos, cardioversores e desfibriladores implantáveis.

Ainda em implantes, saliente-se a engenharia tecidual, a área da ciência especializada em aplicar conhecimentos de biologia, física e química no desenvolvimento de tecidos artificiais a serem inseridos no corpo humano, como, por exemplo, no desenvolvimento de pele artificial, cartilagens e tecidos ósseos, geralmente a partir de células do próprio paciente. Esse campo de pesquisa, que emergiu a partir dos anos 1990 para corrigir as limitações do enxerto de tecidos e do uso de materiais sintéticos, tem crescido significativamente nos últimos anos (Engenharia..., 2013).

Com o desenvolvimento da ciência de materiais, da engenharia biológica, da biologia das célulastronco e da biologia molecular, o potencial da engenharia de tecidos para acelerar a regeneração óssea tem se tornado uma possibilidade efetiva.

\section{Odontologia}

O mercado mundial de odontologia era de US\$ 22 bilhões em 2013, estimando-se que atinja o montante de US\$ 30 bilhões em 2018 (Worldwide Medical..., 2013).

As perspectivas para o crescimento desse segmento são extremamente positivas em função, entre outros, do envelhecimento populacional, da conscientização do consumidor, de mudanças culturais e de inovações no âmbito das práticas restaurativas e cirúrgicas (Judy \& Levin, 2010).

No Brasil, em 2013 esse mercado representava US\$ 442 milhões, e as previsões indicam que em 2018 estará no patamar de US\$ 773 milhões. No país, o crescimento desse segmento tem sido significativo e as tendências indicam que deverá se manter nos próximos anos. De 2013 a 2018, por exemplo, as projeções indicam uma evolução positiva de 75\%. Demanda reprimida, crescente envelhecimento da população, aumento da demanda por odontologia estética, crescente preocupação com a saúde bucal e distribuição de renda são tidos como as principais razões para esse comportamento. A título de exemplo, o número de beneficiários de planos odontológicos passou de quatro milhões em 2003 para 18 milhões em 2012 (Rosseto, 2013).

\footnotetext{
${ }^{5}$ Reunião de especialistas em órteses e próteses. ABDI, Rio de Janeiro, fev. 2014.
} 
O segmento é formado por mais de uma centena de empresas, 109 delas associadas à Abimo, sendo que, destas, mais de 70\% estão sediadas no estado de São Paulo (Abimo, 2014). 88\% das vendas destinam-se ao mercado nacional privado. Em 2009, dos oitocentos mil implantes realizados e 2,4 milhões de componentes protéticos e acessórios utilizados, 90\% foram fornecidos pela indústria nacional. O mercado público é responsável por 10,5\% das vendas do segmento (Rohan, 2013), mas essa participação deverá crescer em função de compras governamentais.

Saliente-se, a esse respeito, uma importante ação governamental cristalizada na Política Nacional de Saúde Bucal - Brasil Sorridente, um programa do Ministério da Saúde. De modo a garantir ações de promoção, prevenção e recuperação da saúde bucal, o Brasil Sorridente reúne uma série de ações para ampliação do acesso ao tratamento odontológico gratuito, no âmbito do SUS. As principais linhas de ação do programa são a implantação de equipes de saúde bucal no âmbito da Estratégia Saúde da Família, de centros de Especialidades Odontológicas (CEOs) e de laboratórios regionais de próteses dentárias (Brasil, 2014).

Lançado em março de 2004, o programa já beneficiou quase oitenta milhões de brasileiros, mil CEOs foram inaugurados e outros 205 estão em fase de construção. Em 2013, mais de 415 mil próteses dentárias foram entregues, por intermédio dos laboratórios regionais de próteses dentárias presentes em 1.465 municípios. Somente em 2013, o Ministério da Saúde investiu R\$ 1 bilhão, em todo o país, em recursos destinados às equipes de saúde bucal e também em investimentos nesses centros (CFO, 2009).

Embora ainda tenha uma representação modesta, a participação das vendas do segmento no mercado externo tem sido crescente. Aliás, esse é o único segmento no âmbito da indústria de equipamentos médicos que apresenta sistematicamente superávit na balança comercial - a exceção se deu em 2013, quando houve déficit associado à crise internacional. A evolução do saldo comercial de 2009 a 2013 do segmento de odontologia pode ser visualizada na Tabela 9.

Tabela 9 - Evolução do saldo comercial do segmento de odontologia. Brasil - 2009-2013 (em US\$ milhões)

\begin{tabular}{|l|c|c|c|c|c|}
\hline & 2009 & 2010 & 2011 & 2012 & \multicolumn{1}{c|}{2013} \\
\hline Odontologia & 24,6 & 25,2 & 6,3 & 13,5 & $-14,1$ \\
\hline $\begin{array}{l}\text { Outros segmentos } \\
\text { Total da indústria } \\
\text { de equipamentos } \\
\text { médicos }\end{array}$ & $-2.256,3$ & $-3.059,2$ & $-3.365,5$ & $-3.748,9$ & $-4.149,3$ \\
\hline
\end{tabular}

Fonte: Brazilian Health Devices, 2014.

Mais de 56\% das empresas do segmento vendem para o mercado externo, exportando para 180 países. Entre os produtos exportados, destacam-se instrumentos e aparelhos de odontologia, cadeiras de dentista, próteses de acrílico, artigos e dispositivos para próteses dentárias, brocas, aparelhos de raios X, entre outros produtos para obturação dentária. Alemanha, EUA e países da América do Sul são os principais mercados consumidores. Venezuela, Bolívia, Argentina, Peru e Chile respondem, em conjunto, por 28,5\% das exportações brasileiras (Garcia, 2009). 
Entre as principais tendências tecnológicas para o segmento, é de se notar o crescente uso de TICs, o que aprofundará a relação entre dentista e laboratório protético, estimulará novas abordagens de diagnóstico e tratamento e promoverá a crescente digitalização da odontologia. Internet, vídeo chat, fotografia e design digital, imagem 3D, software de projeto, scanners, moldagem digital, entre outros avanços, estimularão um trabalho crescentemente colaborativo ao longo do processo, de tal modo que os dentistas possam enviar eletronicamente medições e imagens para o laboratório, a restauração seja projetada virtualmente e, no final, o único produto a ser enviado para o consultório odontológico seja a prótese dentária (Trends..., 2012).

Uma das razões do aprofundamento da comunicação laboratório-dentista é a explosão de novas tecnologias e de materiais. A variedade de opções restaurativas exige que o clínico e o laboratório tomem uma série de decisões conjuntas em cada etapa do processo. Aspectos tais como o material a ser usado na restauração, se ela será toda de metal ou metalocerâmica - por exemplo, de PFM (porcelainfused-to-metal) -, são objeto de decisões a serem tomadas em conjunto. Existem também diversas opções cerâmicas tais como CAD/CAM (computer-aided design and computer-aided manufacturing) versus restaurações cerâmicas prensadas, formas monolíticas ou em camadas, modelos virtuais versus modelos tradicionais. A decisão por prótese ou por implante afeta significativamente todos os fatores mencionados (Trends..., 2012).

Zircônia e dissilicato de lítio são os materiais mais promissores nessa área. Zircônia apresenta como vantagens excelente estética e biocompatibilidade, ausência de margem metálica, alta fidelidade marginal, elevada resistência à flexão e ruptura e baixa condutibilidade térmica. Dissilicato de lítio, por sua vez, oferece excelente resistência e aparência estética e é facilmente usinável. Outra tendência situa-se no campo dos compósitos - por exemplo, resina com nanocristais (Vieira, 2011).

Inovações no campo de materiais odontológicos objetivando melhorar a estética e a resistência dos materiais, bem como facilitar e ampliar sua utilização, permanecerão constantes nos próximos anos.

Outra área de crescimento extremamente promissora é a de implantes. De acordo com a American Association of Oral and Maxillo Facial Surgeons, 69\% dos adultos com idades entre 35 a 44 anos perderam pelo menos um dente permanente e $26 \%$ dos adultos com idade de 74 anos perderam todos os dentes permanentes (Judy \& Levin, 2010).

Estima-se que em 2018 o mercado mundial de implantes seja da ordem de US\$ 9,1 bilhões. Melhoria da qualidade e da facilidade de colocação, o que tem significado taxas extremamente elevadas de sucesso para essa tecnologia, questões demográficas, aspectos estéticos, diminuição de contraindicações do tratamento e redução do tempo do procedimento, entre outras, são vistas como as principais razões para o crescimento potencial dessa área (Rohan, 2013).

Sobressai, entre as principais tendências tecnológicas, o desenvolvimento de revestimentos da superfície de implantes para acelerar o processo de integração óssea com nanotecnologia e/ou associação de fatores de crescimento (biomoléculas), ou mesmo com medicamentos que acelerem o processo e/ou evitem infecção. 
Existe um grande potencial para a cura de fraturas do complexo orofacial, o aumento ósseo, o reparo e regeneração da articulação temporomandibular (ATM), o reparo pulpar, a regeneração do ligamento periodontal e a osseointegração de implantes, por meio da engenharia de tecidos. Os tratamentos regenerativos demandam três elementos-chave: matriz extracelular/scaffold (pode ser sintético), células-tronco/progenitoras e sinais morfogenéticos indutores. A grande vantagem da cavidade oral sobre outras partes do corpo, com relação à engenharia de tecidos, é sua fácil observação (Engenharia..., 2013).

Registre-se que já foi criado um dente completo por uma empresa norte-americana denominada Dentigenix, que "tem uma série de programas de engenharia de tecidos: DTx 41, para a remineralização do esmalte; DTx 21, para a remineralização da dentina, e DTx DR -1, para a indução local de dentina" (Engenharia..., 2013).

Um dos grandes objetivos da odontologia restauradora é a preocupação constante dos pesquisadores em encontrar um material que apresente adesão às estruturas dentárias, impedindo assim a infiltração de fluidos bucais e microrganismos que possam comprometer as estruturas remanescentes. Cimento de fosfato de zinco, resinoso, de óxido de zinco e eugenol, de hidróxido de cálcio e de ionômero de vidro têm sido os materiais mais empregados e estudados (Equipamentos Odontológicos, 2006).

Ainda no campo dos materiais, sobressai o desenvolvimento de biomateriais (apatita carbonatada, por exemplo) que sejam absorvíveis e promovam a regeneração óssea, de materiais dentários com maior vida útil e de elementos estéticos.

A convergência entre avanços biomédicos e odontologia também é indicada como uma tendência futura. A odontologia estará cada vez mais dependente de testes de diagnóstico e de soluções farmacêuticas que provejam ao paciente os melhores resultados. Essas soluções farmacêuticas podem incluir testes de câncer oral, antibióticos em periodontia, tratamento químico de doenças periodontais e mesmo formas de estética odontológica (Trends..., 2012).

O Brasil é o segundo maior mercado de implante dentário do mundo (atrás apenas dos EUA), avaliado em 2012 em U\$ 260 milhões de dólares e com expectativa de atingir U\$ 430 milhões em 2016. Por ano, cerca de 800 mil implantes odontológicos são consumidos no Brasil, além de 2,4 milhões de acessórios e componentes protéticos (Rosseto, 2013).

O desempenho competitivo das empresas nacionais faz desse segmento uma das áreas mais promissoras no âmbito da indústria de equipamentos médicos. Além do número de empresas atuantes, existem no país, por exemplo, 211 faculdades públicas e privadas de odontologia e 1.778 laboratórios de prótese dentária (CFO, 2009). Em termos de publicações científicas na área, já em 2006 o Brasil havia ultrapassado países como a Suíça e a Suécia, ocupando a $15^{a}$ posição mundial (Dias, 2008). Essas condições claramente indicam que esse é um segmento que tem todo o potencial de se destacar em termos de capacitação inovativa e produtiva, reforçadas pelos seguintes fatores:

1) atualmente, $11 \%$ da população brasileira nunca foram ao dentista e praticamente $85 \%$ não têm nenhum tipo de assistência odontológica; 
2) faltam mecanismos eficientes de financiamento e de gestão do sistema, o que faz com que o Brasil, mesmo tendo a maior oferta de dentistas do mundo (220 mil), não consiga fornecer assistência odontológica de forma democrática;

3) o aumento dos empregos formais e o aquecimento do mercado de trabalho têm significado aumento do benefício odontológico por parte das empresas;

4) é precário o acesso ao sistema público de assistência odontológica;

5) o mercado brasileiro é considerado incipiente quando comparado com países maduros; nos EUA, por exemplo, $60 \%$ da população contam com planos odontológicos, ao passo que no Brasil esse percentual não chega a 10\% (Rosseto, 2013).

\section{Conclusão}

Há ampla evidência, baseada especialmente nos países europeus e nos EUA, de que as novas tecnologias médicas são um dos principais responsáveis pelo aumento dos custos dos sistemas de saúde e, aparentemente, a solução mais óbvia é direcionar os sistemas de saúde no caminho do uso mais racional de tecnologias médicas e, de preferência, optando-se por tecnologias mais tradicionais e menos caras. Assim, nos países europeus a pressão pela adoção de modelos alternativos de financiamento do gasto com a saúde tem sido cada vez maior (Leão, Oliveira \& Albornoz, 2008).

A maioria dos sistemas públicos de saúde elimina o poder de escolha dos pacientes sobre os tratamentos e tecnologias que podem ser usados, e a preocupação crescente com o problema do gasto público com saúde faz dos sistemas públicos de saúde um ambiente pouco propício à introdução e incorporação de novas tecnologias médicas. Na Comunidade Europeia, por exemplo, a assistência à saúde é caracterizada por tratamentos de baixa intensidade tecnológica, e a incorporação de novas tecnologias pelos sistemas de saúde é amplamente refreada pela necessidade de contenção do gasto público e por uma natural burocracia em processos públicos de aquisição e implementação de novas soluções tecnológicas de tratamento. Os EUA, por sua vez, têm um sistema de assistência à saúde majoritariamente privado, caracterizado por tratamentos extremamente intensivos em tecnologia, o que torna o país o mercado mais atrativo do mundo para equipamentos e materiais de uso em saúde.

Portanto, apesar de haver um esforço muito grande por parte dos governos e das empresas em prol do avanço tecnológico e da competitividade de seus produtos no mercado mundial, o mercado público de equipamentos de uso em saúde está assentado na necessidade de tecnologias custo-eficazes que possam atender de forma adequada às demandas que se apresentam.

O gasto com saúde nos EUA alcança a marca de aproximadamente 17\% do produto interno bruto (PIB), mas é financiado majoritariamente por recursos privados (65\%), ao passo que na Europa o gasto com saúde responde por $10 \%$ do PIB, sendo que apenas $17 \%$ desse gasto vêm da iniciativa privada. No Brasil, o CEIS responde por aproximadamente 9\% do PIB. Assim, as possibilidades de financiamento e expansão dos gastos com saúde nos EUA são mais flexíveis e independem da capacidade fiscal do Estado para angariar recursos para prover o sistema de saúde público (WHO, 2012).

Nos casos europeu e brasileiro, nos quais responde pela maioria esmagadora do gasto com saúde, o Estado desempenha um papel importantíssimo nas sinalizações de mercado no que diz respeito à 
inovação tecnológica nas indústrias e à expansão dos mercados de saúde, bem como à incorporação de novas tecnologias e tratamentos pelos sistemas de saúde. E atua como agente regulador e fiscalizador dos programas privados de assistência à saúde, além de ser, ele próprio, o maior provedor de serviços de saúde. Por outro lado, de acordo com Gadelha (2003), o Estado constitui uma instância determinante da dinâmica industrial do complexo, graças a seu elevado poder de compra de bens e serviços, ao seu poder de indução e às atividades regulatórias que desempenha, em forte interação com a sociedade civil organizada.

Diante disso, pode-se concluir que o Brasil enfrenta um grande desafio na área da inovação tecnológica em produtos e serviços para saúde, pois tem que lidar, por um lado, com o trade-off entre a difusão acelerada de novos tratamentos, procedimentos médicos e soluções tecnológicas (além da escalada em nível global da competitividade das indústrias do setor), e por outro com a necessidade de racionalizar o uso abusivo e irracional de novas tecnologias em saúde, contendo um dos principais fatores da crescente pressão dos gastos em saúde sobre o orçamento público e, concomitantemente, no déficit comercial.

Torna-se imperiosa uma ação efetiva e contrabalançada do Estado na construção de um sistema universal de saúde, que tanto atenda às crescentes demandas sanitárias da população quanto promova o desenvolvimento inovativo e produtivo da indústria brasileira de equipamentos e materiais médico-hospitalares e odontológicos. Trata-se de uma área estratégica por seu potencial intrínseco de promover o adensamento do sistema nacional de inovação e de ampliar a competitividade da indústria como um todo. Em virtude da grande variedade de produtos e serviços e da constante interação da indústria de equipamentos médicos com outros setores em geral, cria-se um modelo de convergência tecnológica que, efetivamente, forma a base para uma importante fonte geradora de inovação. Constitui-se, igualmente, em área estratégica no âmbito da saúde por ser responsável pela oferta permanente de novos de equipamentos e materiais que propiciem aumento da qualidade dos padrões de tratamento e diagnóstico para que estes sejam mais efetivos, mais rápidos, mais seguros e menos invasivos.

O fortalecimento e a consolidação da indústria de equipamentos e materiais médico-hospitalares e odontológicos impõem-se, ademais, como condição absolutamente primordial para a redução da vulnerabilidade da política de saúde. Esta não pode depender tão fortemente de importações com gasto excessivo de divisas, o que a torna sujeita às oscilações do mercado financeiro internacional e refém de estratégias competitivas completamente alheias ao interesse nacional. Do mesmo modo, o apoio ao seu desenvolvimento representa a possibilidade de se articular a política de saúde com a política industrial e tecnológica, buscando-se a convergência entre a lógica sanitária e a econômica, de forma a associar o financiamento social com o desenvolvimento tecnológico e industrial nacional. 


\section{Referências}

AGÊNCIA BRASILEIRA DE DESENVOLVIMENTO INDUSTRIAL (ABDI). Estudo Prospectivo: cadeia de equipamentos médicos, hospitalares e odontológicos. Brasília: ABDI, 2009. (Cadernos da Indústria ABDI, VIII)

AGÊNCIA BRASILEIRA DE DESENVOLVIMENTO INDUSTRIAL (ABDI). Sistemas Aplicados a Saúde Humana. Brasília: ABDI, 2010 (Cadernos Temáticos TICs, 4)

AGÊNCIA NACIONAL DE VIGILÂNCIA SANITÁRIA (ANVISA). Relatório Gerencial Datavisa, GGTPS. Brasília: Anvisa, 2012.

ALBUQUERQUE, E. \& CASSIOLATO, J. As Especificidades do Sistema de Inovação do Setor Saúde: uma resenha da literatura como introdução a uma discussão sobre o caso brasileiro. Belo Horizonte: Federação de Sociedades de Biologia Experimental, 2000. (Estudos Fesbe, 1)

ASSOCIAÇÃO BRASILEIRA DA INDÚSTRIA DE ARTIGOS E EQUIPAMENTOS MÉDICOS, ODONTOLÓGICOS E HOSPITALARES E DE LABORATÓRIO (ABIMO). Dados Econômicos. São Paulo: Abimo, 2013a. Disponível em: <www.abimo.org.br/modules/content/pdf/pdf.php?page=dados-economicos > . Acesso em: 1 abr. 2014.

ASSOCIAÇÃO BRASILEIRA DA INDÚSTRIA DE ARTIGOS E EQUIPAMENTOS MÉDICOS, ODONTOLÓGICOS E HOSPITALARES E DE LABORATÓRIO (ABIMO). Análise de Estrutura Setorial de Artigos e Equipamentos Médicos, Odontológicos, Hospitalares e de Laboratório. São Paulo: FGV Projetos, 2013b.

ASSOCIAÇÃO BRASILEIRA DA INDÚSTRIA DE ARTIGOS E EQUIPAMENTOS MÉDICOS, ODONTOLÓGICOS E HOSPITALARES E DE LABORATÓRIO (ABIMO). Site. Disponível em: <www.abimo.org.br>. Acesso em: 1 mar. 2014.

BANCO NACIONAL DE DESENVOLVIMENTO ECONÔMICO E SOCIAL (BNDES). Atuação do BNDES no apoio à indústria de equipamentos e tecnologias para saúde. In: CONGRESSO DE INOVAÇÃO EM MATERIAIS E EQUIPAMENTOS PARA SAÚDE, 2, 2013, São Paulo. Disponível em: <www.cimes.org.br/uploads/paginas/file/ palestras/Jo\%C3\%A3o\%20Paulo\%20Pieroni\%20-\%20BNDES.pdf>. Acesso em: 20 jan. 2014.

BRASIL. Decreto Presidencial de 12 maio 2008. Cria, no âmbito do Ministério da Saúde, o Grupo Executivo do Complexo Industrial da Saúde - GECIS, e dá outras providências. Brasília, Diário Oficial da União, 2008.

BRASIL. Presidência da República. Plano de Inovação do Brasil. Plano Brasil Maior. Inovar para competir. Competir para crescer: plano 2011/2014, 2011. Disponível em: <www.abic.com.br/publique/media/PlanoEstrat_Cafes_Brasil_Plano_BrasilMaior_RitaMilagres_MDIC.pdf $>$. Acesso em: abril 2014.

BRASIL. Ministério da Ciência, Tecnologia e Inovação. Estratégia Nacional de Ciência, Tecnologia e Inovação 2012-2015: balanço das atividades estruturantes 2011. Brasília: Ministério da Ciência, Tecnologia e Inovação, 2012. Disponível em: <www.mct.gov.br/upd_blob/0218/218981.pdf>. Acesso em: 29 jul. 2014.

BRASIL. Ministério da Saúde. Brasil Sorridente. Disponível em: <http://dab.saude.gov.br/portaldab/ape_brasil_sorridente.php>. Acesso em: mar. 2014.

BRAZILIAN HEALTH DEVICES. Dados do mercado, 2014. Disponível em: < http://brazilianhealthdevices.com. br/market>. Acesso em: 12 mar. 2014.

CASSIOLATO, J. E. \& LASTRES, H. M. M. Sistemas de inovação: políticas e perspectivas. Parcerias Estratégicas, 8: 237-255, 2000. Disponível em: <www.cgee.org.br/parcerias/p08.php>. Acesso em: 29 jul. 2014.

CONSELHO FEDERAL DE ODONTOLOGIA (CFO). Rio de Janeiro, 2009. Disponível em: < http://cfo.org.br/ noticias>. Acesso em: mar. 2014.

DIAS, A. A. Pesquisa Odontológica no Brasil: características da produção científica no século XXI, 2008. Tese de Doutorado, Natal: Universidade Federal do Rio Grande do Norte. Disponível em: <ftp://ftp.ufrn.br/pub/ biblioteca/ext/bdtd/AldoAD.pdf> . Acesso em: mar. 2014. 
ENGENHARIA de tecidos e pesquisa com células-tronco. Portal Educação, 21 fev. 2013. Disponível em: <www. portaleducacao.com.br/odontologia/artigos/34651/engenharia-de-tecidos-e-pesquisa-com-celulas-tronco $>$. Acesso em: mar. 2014.

EQUIPAMENTOS Odontológicos. EASY - Equipamentos Odontológicos. Materiais obturadores em endodontia, 2006. Disponível em: <www.easy.odo.br/casos_clinicos/materiais-obturadores-em-endodontia-novastendencias/>. Acesso em: mar. 2014.

EUROPEAN COMMISSION. The 2007 EU Industrial R\&D Investment Scoreboard. Luxembourg: European Comission, 2007.

EUROPEAN COMMISSION. The 2012 EU Industrial R\&D Investment Scoreboard. Luxembourg: European Comission, 2013.

FURTADO, C. Dialética da Inovação: a economia da tecnologia. Rio de Janeiro: Fundo de Cultura, 1964.

GADELHA, C. A. G. O complexo industrial da saúde e a necessidade de um enfoque dinâmico na economia da saúde. Ciência \& Saúde Coletiva, 8(2): 521-535, 2003.

GADELHA, C. A. G. Gecis dos Equipamentos e Materiais de Uso em Saúde (produtos para a saúde). In: REUNIÃO DO CONSELHO DE COMPETITIVIDADE DO COMPLEXO DA SAÚDE, $6^{\circ}$ Encontro do Grupo Executivo do Complexo Industrial da Saúde. Apresentação institucional, 2013, Brasília.

GADELHA, C. A. G. et al. A Dinâmica do Sistema Produtivo da Saúde: inovação e complexo econômico-industrial. Rio de Janeiro: Editora Fiocruz, 2012.

GARCIA, R. M. O voo do mercado odontológico. Dental Press, 2009. Disponível em: <www.dentalpress.com. br/v5/noticias.php?id=5681>. Acesso em: mar. 2014.

GRUPO DE INOVAÇÃO EM SAÚDE (GIS). Escola Nacional de Saúde Pública Sergio Arouca. Fundação Oswaldo Cruz. Dados da Rede Alice/MDIC, 2014. Disponíveis em: < http://aliceweb.desenvolvimento.gov.br>. Acesso em: jan. 2014.

GUTIERREZ, R. M. V. \& ALEXANDRE, P. V. M. Complexo Industrial da Saúde: uma introdução ao setor de insumos e equipamentos de uso médico. Rio de Janeiro: BNDES, 2004.

HOSPITAL DA LUZ: Espírito Santo Saúde, 2014. Disponível em: <www.hospitaldaluz.pt/pt/centros-multidisciplinares/centro-de-cirurgia-robotica-e-cirurgia-minimamente-invasiva/o-centro/cirurgia-robotica/>. Acesso em: 12 mar. 2014.

INSTITUTO BRASILEIRO DE GEOGRAFIA E ESTATÍSTICA (IBGE). Pesquisa Industrial de Inovação Tecnológica 2003. Rio de Janeiro: Ministério do Planejamento, Orçamento e Gestão.

INSTITUTO BRASILEIRO DE GEOGRAFIA E ESTATÍSTICA (IBGE). Pesquisa Industrial de Inovação Tecnológica 2005. Rio de Janeiro: Ministério do Planejamento, Orçamento e Gestão.

INSTITUTO BRASILEIRO DE GEOGRAFIA E ESTATÍSTICA (IBGE). Pesquisa Industrial de Inovação Tecnológica 2011. Rio de Janeiro: Ministério do Planejamento, Orçamento e Gestão.

INSTITUTO DE ESTUDOS E MARKETING INDUSTRIAL (IEMI). Estudo Setorial da Indústria de Equipamentos Odonto-Médico-Hospitalar e Laboratorial no Brasil. São Paulo: Iemi, Abimo, 2010.

JUDY, K. W. M. \& LEVIN, R. P. Trends in implant dentistry. The Dentistry,100(12), 2010. Disponível em: <www. dentaleconomics.com/articles/print/volume-100/issue-12/features/trends-in-implant-dentistry.html > . Acesso em: mar. 2014.

KAWACHI, E. et al. Biocerâmicas: tendências e perspectivas de uma área interdisciplinar. Campinas: Unicamp, 2000. Disponível em: <www.scielo.br/pdf/qn/v23n4/2652.pdf>. Acesso em: 12 mar. 2014. 
LANDIM, A. et al. Equipamentos e Tecnologias para Saúde: oportunidades para uma inserção competitiva da indústria brasileira. Rio de Janeiro: BNDES, 2013.

LEÃO, R.; OLIVEIRA, E. \& ALBORNOZ, L. Estudo Setorial: setor de equipamentos e materiais de uso em saúde. Brasília: Secretaria de Ciência, Tecnologia e Insumos Estratégicos, Departamento de Economia da Saúde, Coordenação Geral de Economia da Saúde, 2008.

MEDICAL equipment industry: the new trends and focuses. Pharmaceutical Drug Manufacturers, 5 mar. 2010. Disponível em: <www.pharmaceutical-drug-manufacturers.com/articles/medical-equipment-trends.html> . Acesso em: 29 jul. 2014.

MEDICAL equipment and supplies report 2013: a Clearwater healthcare team report. Clearwater, 2012. Disponível em: <www.kurmannpartners.com/fileadmin/user_upload/MR-MedTech/2013_Medical_Equipment_Supplies_final.pdf >. Acesso em: 13 fev. 2014.

NETO, H. L. Monitoramento da Qualidade dos Implantes Ortopédicos Comercializados no Brasil e a Importância da Estruturação da Rede Multicêntrica para Avaliação de Implantes Ortopédicos. Rio de Janeiro: Centro de Ensino e Pesquisa do Pró-Cardíaco, 2007.

NÚCLEO DE ASSESSORIA, CAPACITAÇÃO E ESPECIALIZAÇÃO (NASCE). Instrumental cirúrgico ortopédico. Disponível em: <www.nascecme.com.br/artigos/ortopedia.pdf>. Acesso em: 12 mar. 2014.

OFTALMOLOGIA: PACS (Picture Archiving and Communication System). Disponível em: <www. linkedin.com/groups/Qual-objetivo-do-pacs-4887656.S.220194297?qid=0f94d8a9-ec25-4f29-99a2b452f988d8ea\&trk=groups_guest_most_popular-0-b-ttl\&goback=\%2Egmp_4887656>. Acesso em: 23 abr. 2014.

OLIVEIRA, E. J. V. \& BUTTON, V. L. S. N. Uma estratégia de desenvolvimento para o sistema nacional de inovação de produtos médicos. Revista Brasileira de Engenharia Biomédica, 28(2): 124-139, 2012.

OLIVEIRA, G. B. Algumas considerações sobre inovação tecnológica, crescimento econômico e sistemas nacionais de inovação. Revista FAE, 4(3): 5-12, 2001.

PAMMOLLI, F. et al. Medical devices competitiveness and impact on public health expenditure. Rome and Florence: CERM - Competitiveness, Markets and Regulation, University of Florence, 2005. Disponível em: <http:// mpra.ub.uni-muenchen.de/16021/1/MPRA_paper_16021.pdf>. Acesso em: 15 jan. 2014.

PAULA, P. Brasil terá primeira fábrica de equipamentos para radioterapia da América Latina. Portal da Saúde. Disponível em: < http://portalsaude.saude.gov.br/index.php/cidadao/principal/agencia-saude/18385-brasiltera-primeira-fabrica-de-equipamentos-para-radioterapia-da-america-latina >. Acesso em: 5 jul. 2014.

PIERONI, J. P; REIS, C. \& SOUZA, J. O. B. A Indústria de Equipamentos e Materiais Médicos, Hospitalares e Odontológicos: uma proposta de atuação do BNDES. Rio de Janeiro: BNDES, 2010.

RASMUSSEN, J.; ANNERSTEDT, J. \& GRAHAM, H. Innovation financing in the European medical device sector. In: INTERLACE-INVENT, 2007, Denmark. (Work-package n. 1).

REDE ALICE/MIDC. Disponível em: <http://aliceweb.mdic.gov.br/>. Acesso em: jan. 2014.

ROHAN. Dental implants and prosthetics market. Markets and Markets, 2013. Disponível em: <www.marketsandmarkets.com/PressReleases/dental-implants-market.asp>. Acesso em: mar. 2014.

ROSSETO, F. Odontologia em pleno voo. Gestão em Saúde Diagnóstico web, mar. 2013. Disponível em: <www. diagnosticoweb.com.br/blogs/fabio-rossetto/odontologia-em-pleno-voo.html>. Acesso em: mar. 2014.

SELAN, B.; PORTO, G. \& KANNEBLEY, S. Parque tecnológico de Ribeirão Preto. Relatório Setorial de Inovação Tecnológica: indústria de produtos e equipamentos médico-hospitalares e odontológicos brasileira. Ribeirão Preto: Fipase, 2007. 
THE WORLD Medical Markets Fact Book 2013. Market Watch, 14 ago. 2013. Disponível em: <www.marketwatch. com/story/the-world-medical-market-fact-book-2013-2013-08-14> . Acesso em: 20 jul. 2014.

TRENDS in dentistry. Dentalaegis, 3(11), 2012. Disponível em: <www.dentalaegis.com/idt/2012/12/trendsin-dentistry >. Acesso em: mar. 2014.

VIEIRA, B. Zircônia como Material de Escolha para Infraestrutura de Próteses Fixas, 2011. Monografia de Especialização em Prótese Dentária, Florianópolis: Instituto de Ciências da Saúde, Faculdades Integradas do Norte de Minas, Associação Educativa do Brasil. Disponível em: <www.cursospos.com.br/arquivos_biblioteca/7176 a3876e0e46bde950b009f7ce94c9105e1113.pdf > . Acesso em mar. 2014.

WORLD HEALTH ORGANIZATION (WHO). Site. Disponível em: <www.who.int/en/> . Acesso em: maio 2012. WORLDWIDE MEDICAL Market Forecasts to 2018. Great Britain: Espicon Business Intelligence, 2013. 